Illinois State University

ISU ReD: Research and eData

Theses and Dissertations

$12-26-2019$

\title{
Taking Advantage of Second Chances Through Reassessment
}

Benjamin D. Lee

Illinois State University, benjamin.lee@olympia.org

Follow this and additional works at: https://ir.library.illinoisstate.edu/etd

Part of the Education Commons

\section{Recommended Citation}

Lee, Benjamin D., "Taking Advantage of Second Chances Through Reassessment" (2019). Theses and Dissertations. 1197.

https://ir.library.illinoisstate.edu/etd/1197

This Dissertation is brought to you for free and open access by ISU ReD: Research and eData. It has been accepted for inclusion in Theses and Dissertations by an authorized administrator of ISU ReD: Research and eData. For more information, please contact ISUReD@ilstu.edu. 


\section{TAKING ADVANTAGE OF SECOND CHANCES THROUGH REASSESSMENT}

\section{BENJAMIN D. LEE}

\section{Pages}

A critical factor in Skills-Based Reporting is the opportunity for students to reassess in an effort to enhance learning. In this middle school, however, few students were taking advantage of the opportunity to reassess. The study focused specifically on investigating how Skills-Based Reporting impacted student mindset and to what extent parent involvement played a role in whether students chose to reassess or not to reassess. Students and parents from this middleschool setting shared their perceptions on Skills-Based Reporting. For use in the quantitative phase of the, a student survey was administered to each student in the middle school to collect information on why they choose or do not choose to reassess. Semi-structured interviews were used to gather data from parents for the qualitative phase of this study. Findings from the study indicated that students generally believed they understood and demonstrated a Growth Mindset. Students believed it was possible for them to change their assessments score, level of effort and their ability to learn. Student participants indicated they only reassessed when they felt their score was not an accurate reflection of their learning. Sometimes, a score of a ' 2 ' matched the student view of their learning and should not automatically indicate the lack of a Growth Mindset. However, results suggested students do not fully embrace the central idea that they own their learning. Parent participants reported they were the ones that more often required reassessment rather than the teachers. A parent's high expectations are likely to result in more frequent reassessments, which does not necessarily reflect a Growth Mindset for the student. 
KEYWORDS: Competency-Based Education, Mindset, Perseverance, Reassessment, SkillsBased Reporting, Standards-Based Grading 
BENJAMIN D. LEE

A Dissertation Submitted in Partial

Fulfillment of the Requirements

for the Degree of

DOCTOR OF EDUCATION

Department of Educational Administration and Foundations

ILLINOIS STATE UNIVERSITY

2020 
Copyright Benjamin D. Lee 2020 
TAKING ADVANTAGE OF SECOND CHANCES THROUGH REASSESSMENT

BENJAMIN D. LEE

COMMITTEE MEMBERS:

Guy Banicki, Chair

Lydia Kyei-Blankson

Dianne C Gardner Renn

Andrew S Wise 


\section{ACKNOWLEDGMENTS}

I would like to offer my sincere gratitude to my dissertation committee for the guidance, flexibility, and encouragement throughout the writing process. You helped me refine my writing, but more importantly, modeled the value of learning. I am forever grateful for your encouragement to embody the Growth Mindset and persevere while challenging conventional thinking.

Above all, I need to thank my family. Thank you to my mom and dad, Dale and Linda, for instilling in me the value of higher education. Your outstanding work ethic helped make education a priority. It is my hope to carry that on for future generations. Thank you to my adorable daughters - Olivia and Sadie. They were patient through all of the evening classes and weekends of daddy working on his writing at school. Thank you for always greeting me with hugs and loving me as only daughters can. That love was the fuel that powered me though.

My most important thank you is for Hannah-my wife and hero. Completely supportive of this quest, she made more sacrifices than anyone. This would never be possible without her taking the lead and being a terrific wife and mother. Hannah-you continually amaze me at your selflessness. I am a better person because of walking through life with you.

B. D. L. 


\section{CONTENTS}

Page

ACKNOWLEDGMENTS

$\begin{array}{ll}\text { CONTENTS } & \text { ii }\end{array}$

TABLES

FIGURES

CHAPTER I: INTRODUCTION TO THE STUDY

Background and Statement of Problem 1

Purpose of Study $\quad 5$

$\begin{array}{ll}\text { Theoretical Framework } & 7\end{array}$

$\begin{array}{ll}\text { Research Questions } & 10\end{array}$

Definition of Terms $\quad 11$

Study Design $\quad 11$

$\begin{array}{ll}\text { Positionality } & 11\end{array}$

$\begin{array}{ll}\text { Summary } & 12\end{array}$

CHAPTER II: LITERATURE REVIEW 14

$\begin{array}{ll}\text { Introduction } & 14\end{array}$

$\begin{array}{ll}\text { Literature Collection Process } & 14\end{array}$

History of Grading in “A”merica 15

$\begin{array}{ll}\text { Purpose of Assessment } & 16\end{array}$

$\begin{array}{ll}\text { Traditional Grading Problems } & 19\end{array}$

$\begin{array}{ll}\text { From Traditional to Emerging... } & 24\end{array}$

Standards Based Grading and Reporting as Best Practice 26 
$\begin{array}{ll}\text { Theoretical Framework } & 34\end{array}$

$\begin{array}{ll}\text { Summary } & 36\end{array}$

$\begin{array}{ll}\text { CHAPTER III: METHODOLOGY } & 38\end{array}$

$\begin{array}{ll}\text { Purpose of the Study } & 38\end{array}$

$\begin{array}{ll}\text { Research Design } & 38\end{array}$

$\begin{array}{ll}\text { Participants and Research } & 40\end{array}$

$\begin{array}{ll}\text { Instrumentation } & 41\end{array}$

$\begin{array}{ll}\text { Data Collection } & 42\end{array}$

$\begin{array}{ll}\text { Data Analysis } & 43\end{array}$

$\begin{array}{ll}\text { Quantitative } & 43\end{array}$

$\begin{array}{ll}\text { Qualitative } & 44\end{array}$

$\begin{array}{ll}\text { Ethical Consideration } & 45\end{array}$

Trustworthiness, Authenticity and Credibility 46

$\begin{array}{ll}\text { Summary } & 47\end{array}$

CHAPTER IV: ANALYSIS OF DATA 48

Students Choice to Reassess or Not to Reassess 49

No Need to Reassess 55

Assessments are Not Easy Enough $\quad 55$

Making Reassessments Mandatory $\quad 56$

$\begin{array}{ll}\text { Time } & 56\end{array}$

$\begin{array}{ll}\text { Teachers Provided More Feedback } & 57\end{array}$

$\begin{array}{ll}\text { Liking the Subject } & 58\end{array}$ 
Parent Involvement in Student Reassessment $\quad 58$

Parents Value Opportunities to Learn $\quad 59$

Second Chances Should Be Based on Effort, Not Entitlement, Because That

Reflects Life Beyond High School $\quad 64$

$\begin{array}{ll}\text { Summary } & 90\end{array}$

CHAPTER V: DISCUSSION, RECOMMENDATIONS, \& CONCLUSIONS 92

$\begin{array}{ll}\text { Summary and Discussion } & 92\end{array}$

$\begin{array}{ll}\text { Student Choice to Reassess or Not } & 92\end{array}$

Parent Involvement in Student Reassessment 95

$\begin{array}{ll}\text { Recommendation for Action } & 96\end{array}$

Contributions to the Body of Literature 98

$\begin{array}{ll}\text { Limitations } & 99\end{array}$

Recommendation for Further Study $\quad 99$

$\begin{array}{ll}\text { Conclusion } & 101\end{array}$

$\begin{array}{ll}\text { REFERENCES } & 103\end{array}$

APPENDIX A: RECRUITMENT LETTER/EMAIL 113

APPENDIX B: INFORMED CONSENT LETTER 114

APPENDIX C: PARENT PERMISSION/ASSENT FORM 116

$\begin{array}{ll}\text { APPENDIX D: STUDENT ASSENT } & 118\end{array}$

APPENDIX E: STUDENT SURVEY PROTOCOL 119

$\begin{array}{ll}\text { APPENDIX F: PARENT INTERVIEW PROTOCOL } & 121\end{array}$ 


\section{TABLES}

Table

Page

1. Student Survey Demographic Information-Questions 1-4

2. Student Survey Results-Questions 5-6

3. Student Survey Results-Questions 7-10

4. Student Survey Results-Question 11

5. Student Survey Results-Question 12

6. Student Survey Results-Questions 13-15

7. Parents Value Opportunities to Learn: Key Terms

8. Second Chances Should Be Based on Effort, Not Entitlement: Key Terms

9. Parents Are Confused About Skills Based Reporting: Key Terms

10. Parents Who Are Involved Have High Expectations for a Growth Mindset and Achievement: Key Terms 


\section{FIGURES}

Figure

1. Timeline of Farmersville's Implementation of SBR 2

2. Levels of Learning Descriptors for Skills Based Reporting 3

3. Theoretical Framework 9 


\section{CHAPTER 1: INTRODUCTION OF THE STUDY}

\section{Background and Statement of the Problem}

The Farmersville School District decided to reframe failure. Within its mission to empower learners to recognize growth, lies a unique assessment strategy; one that emphasizes the development of skills. At Farmersville, it matters more that students learn a skill, not when. To hone in on the skill itself, the district uses a scale of 1-2-3-4 to assess students rather than provide traditional grades. If students fall short of the desired proficiency, students can reassess by making adjustments and proving they have learned the skill. Simply put, students try again; an educational mulligan, if you will. The improvements made by students reflect their score. There is no penalty for the previous attempt. Farmersville calls this approach to assessment Skills Based Reporting (SBR).

Skills based reporting is a system designed to promote student ownership of learning. Dr. John Hattie published a book entitled Visible Learning for Teachers (2012) that illustrated results from his meta-analysis of research seeking the strategies that result in the highest impact on student learning. Student ownership of learning was determined to be a key component that generated the highest learning gains. Dr. Hattie found that when students truly own their own learning, they could make three years of growth within a single school year. A self-directed learner is one who owns his or her learning. Self-directed learners know what they are learning, why they are learning it, and what adjustments are necessary to improve the learning process.

Leaders in the Farmersville School District engaged in an extensive study of Hattie's research, complete with themed professional development across the district. Figure 1 displays the timeline of implementation efforts, reflecting the scope and sequence of the District's efforts to adopt this research and enhance student ownership of learning. Elementary report cards 
transitioned to a description of skills to be attained and reported soon thereafter. In order to best facilitate student ownership of learning, Farmersville Middle School employed a Skills Based Reporting system. Driving the reporting system is the belief that the primary goal of assessment is communication to students, parents and teachers. Additionally, assessment reflects what a student knows and is able to do based on clearly established skills. To this end the district is driven by the belief that scoring is timely, accurate, specific and fair. Finally, grading produces information that students can use for self-evaluation, further demonstrating ownership of their own learning.

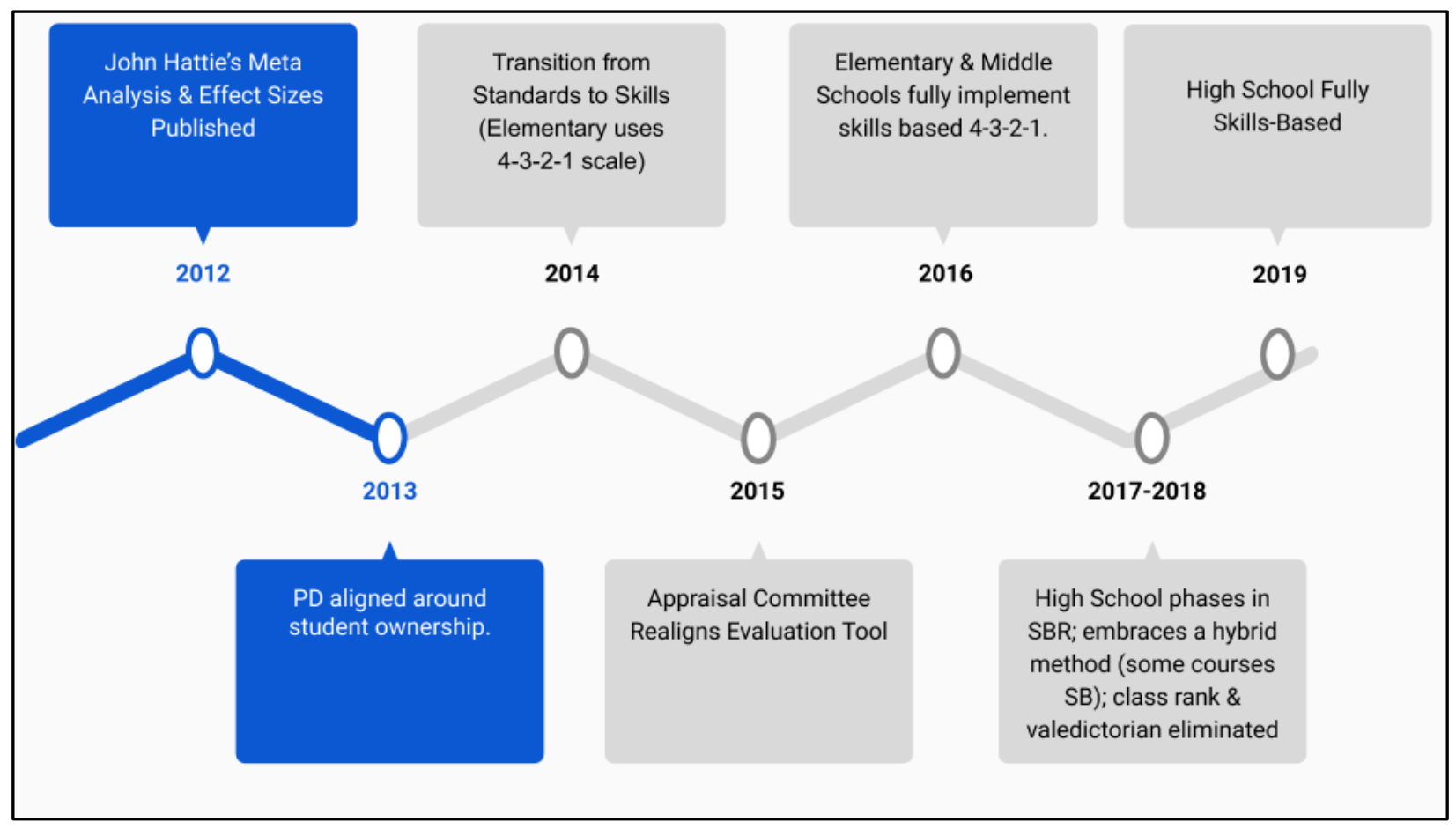

Figure 1. Timeline of Farmersville's Implementation of SBR

Throughout the 2015-2016 school year, teachers at Farmersville Middle School (FMS) worked collectively to identify the most essential skills for students to master and show appropriate growth within their subject and grade level. The teachers read several professional articles on this topic and engaged in a variety of development to prepare for this transition. Next, 
the staff identified three to eight skills on which to focus instructional efforts over the course of a year that were most crucial for student success. Narrowing the focus by prioritizing skills allowed the teachers to dig deeper with the essential skills for their classes. All teachers developed a document breaking each skill down into what students need to know and what students need to be able to do to demonstrate attainment of each skill.

The FMS assessment process was transformed to reflect the new skills-based system. The new assessment and reporting system abandoned the traditional letter grades and instead utilized a numerical rating scale of 4-3-2-1. Figure 2 shows the descriptions of the various levels of skill demonstration.

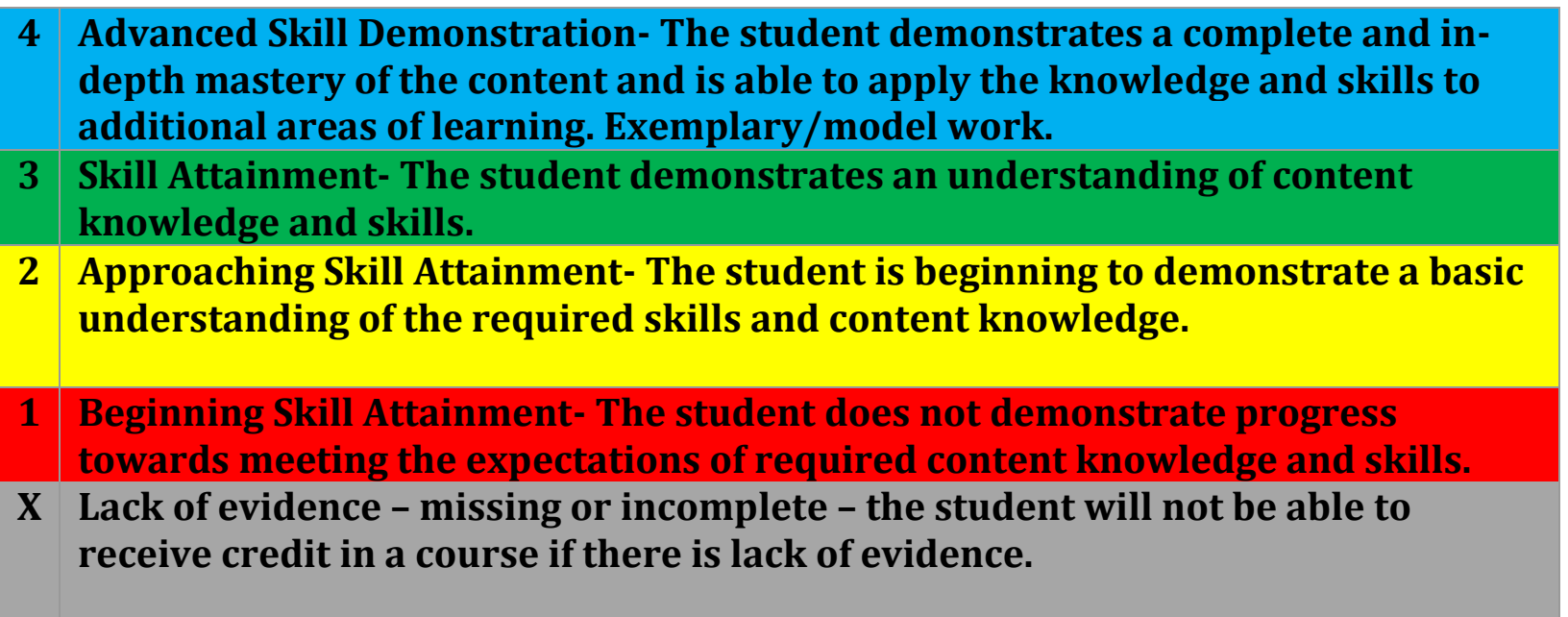

Figure 2. Levels of Learning Descriptors for Skills Based Reporting

Formative assessments take place frequently during an instructional unit and guides teachers in adjusting instructional approach to improve learning. Also known as assessments for learning, formative assessments are typically shorter and are embedded within the learning process (DuFour, DuFour, \& Eaker, 2008). Teachers use these results to help inform their instruction and these can take place either orally, on paper, or by utilizing technology, amongst other methods. Ideally, these checks for understanding take place several times throughout the learning process. Students should use the results to help them focus on what they need to 
improve while still learning about the topic on which they were assessed. Summative assessments, also known as assessments of learning, typically take place at the end of a unit of instruction. Summatives are typically longer and capture a cumulative picture of a student's learning (DuFour, DuFour, \& Eaker, 2008). In a traditional classroom, everything a student does is looked at together and there is one score reported back to the student, even though there may be several skills covered on the assessment. In the FMS Skills Based Reporting environment, the students receive feedback on their performance and a rating on each individual skill on which they are assessed. If a student performs poorly on a summative assessment, there are specific retake procedures that a student has the option of following to reassess.

Despite this tremendous paradigm shift the past three years, the dramatic academic gains have yet to arrive at FMS. Examining local benchmarking data in which all students participate in the fall, winter and spring, only $35 \%$ of students reached grade level targets in reading with fewer (32\%) reaching grade level targets in math. Furthermore, the school's individual report card figures reflected similar results, with $33 \%$ of all students reaching the desired level of proficiency in math and reading combined. In taking a closer look at Skills Based Reporting, I discovered something surprising: students at FMS are not taking advantage of the second chance provided with reassessment. Every student across the school is offered the chance to re-assess if he/she scores a 3 or less in any content area but students currently reassess less than ten percent of the time when taking into account all subject areas and possible reassessment opportunities. They are turning down a second chance to demonstrate the skill. Students are leaving learning on the table! It is no wonder that a mere 30\% of students at Farmersville are meeting or exceeding benchmarks on state (Illinois State Board of Education, 2019) and national (The College Board, 2019) assessments. 
In an effort to discover why, I asked some teachers, parents and students what they thought about this phenomenon. I wanted their input. Did they believe that students are content with underperforming? Are the hurdles to reassessing too large of a burden? In other words, in what ways is the lack of reassessment an individual or an organizational problem? With the aforementioned questions serving as a guide, I decided to explore how SBR shaped instructional processes at FMS.

The Carnegie Project for the Educational Doctorate (CPED) defines a Problem of Practice as "a persistent, contextualized, and specific issue embedded in the work of a professional practitioner, the addressing of which has the potential to result in improved understanding, experience and outcomes practice (Carnegie Project for the Educational Doctorate, 2018)." This problem of students not taking advantage of second chances is specific and persistent meaning substantive examination and modifications are needed. Addressing this problem could be the key that unlocks learning on an individual, organizational and even community-wide scale.

\section{Purpose of Study}

Grading reforms have articulated and emphasized learning standards while tying results to accountability (Reeves, 2011). Grading and reporting, however, remain untethered to the reforms, with traditional grading models still permeating the educational landscape. Existing literature suggests that SBR is a student-centered approach that can produce assessment-capable learners, ultimately enabling productive feedback to improve learning. Creative methods in assigning and evaluating student work has the potential for learning to enter back into the spotlight. When students and teachers recognize their strengths and understand areas for growth, grades become an avenue for the evolution of learning. 
Research on SBR as a best practice at the elementary aged level is becoming more voluminous. While the practice of SBR is gaining traction at the middle school level, that research is still scarce. Since Dweck (2006) wrote on the subject matter the concept of Growth Mindset has shared a parallel rise in popularity along with SBR, yet the research connecting these two ideas remains relatively limited. Even more scarce is the data about SBR's effectiveness with middle and high school students.

On the other hand, there is ample research on the shortcomings of traditional grading practices. Considerable amounts of studies have demonstrated the inaccuracies of the 100-point scale (Goodwin \& Hein, 2016; Guskey, 2015; O'Connor, 2007; O'Connor, 2011; Reeves, 2004; Reeves, 2011; Tucker, 2018), averaging scores (Guskey, 2015; Jung \& Guskey, 2012; Marzano, 2000; McMillan, Myran \& Workman, 2002; Munoz \& Guskey, 2015; O’Connor \& Wormeli, 2011; Reeves, 2004; Scriffany, 2008), using grading as punishment and issuing zeroes to students ( Marzano, 2010; O’Connor \& Wormeli, 2011; Reeves, 2004; Reeves, 2011; Schimmer, 2016; Tucker, 2018; Wormeli, 2011). All of these have been uncovered as not aligning with best practice (Brookhart, 2011; Frey, Fisher \& Hattie, 2018; Guskey, 2009; Guskey, 2015; Guskey \& Jung, 2013; Marzano, 2009; Marzano \& Heflebower, 2011; Reeves, 2008; Reeves, 2013; Schimmer, 2016; Scriffiny, 2008; Townsley, 2018; Vatterott, 2015; Wormeli, 2011).

While the debate on which is the most effective grading practice continues to be hotly contested, a general consensus has been reached about the need for parents to be involved in their child's education. Parent involvement is widely noted by researchers as having a positive effect on student achievement (Baquedano-Lopez, Alexander, \& Hernandez, 2013; Dianis, Jackson, \& Noguera, 2015; Fan, 2001; Forum on Educational Accountability, 2007; Jeynes, 2012; Lyken-Segosebe \& Hinz, 2015; Ravitch, 2013). Students whose parents take an active role 
in their education by demonstrating high expectations and encouragement perform better than those whose parents are uninvolved (Fan, 2014; Hattie, 2012; Tran, 2014). The strong connection between student performance and parent involvement justifies including parents as a variable in this study.

Two main purposes drive this research. First, in this study I intend to uncover the reasons behind students' choice to reassess or not. Second, I examine the role parent involvement plays in student choice to reassess or not. The findings of this study will help educators to be more effective in the implementation of the reassessment system and may have implications for improvement in student learning and academic achievement.

\section{Theoretical Framework}

The theoretical framework applied in this study is a three-pronged approach and comprises Visible Learning Theory, Balanced Assessment Theory and Mindset Theory. As shown in Figure 3, each theory revolves around the framework, an equally important trio of theories that support the framework of the study. First, Visible Learning Theory is derived from educational researcher Dr. John Hattie, whose synthesis of more than 800 meta-analyses covering more than 80 million students resulted in the ranking of instructional strategies by their influence, or effect size (Hattie, 2012). These influences highlighted the need to make teaching and learning visible (Hattie \& Yates, 2014; Hattie, 2012). Visible learning is a combination of relevant and robust high-impact strategies that empowers students and teachers to maximize learning outcomes at a much greater rate than other factors (Visible Learning, 2019).

Balanced assessment is an assessment strategy that recognizes no single assessment yields the comprehensive results necessary to inform and improve practice while fostering school accountability. Therefore, balanced assessments utilize multiple measures of student 
achievement including formative assessments for learning and summative assessments of learning. Balanced assessment also refers to using different types of formative assessments based upon the knowledge and/or skills students are called upon to demonstrate. Rather than relying exclusively on one kind of assessment, schools and teams develop multiple ways for students to demonstrate proficiency (DuFour, DuFour, \& Eaker, 2008). Balanced Assessment continues to frame the work of educational assessments in classrooms, school and district level settings. As a result, students, teachers and educational leaders transform learning through the creative use of assessments (DuFour \& Marzano, 2011; Guskey \& Jung, 2013; Reeves, 2007; Reeves, 2013; Schimmer, 2016).

Two assessment types within the balanced assessment framework include formative assessments and summative assessments. Teachers implement formative assessments during an instructional unit on a frequent basis to assess student learning in real time. Used effectively, formative assessment provides information that helps the teacher adjust instruction to improve student learning. Interim assessments take place in time for teachers to adjust instruction to address any identified gaps in student mastery (DuFour, DuFour, \& Eaker, 2008). However, researchers have found that a more effective approach to designing assessments is for teachers within a school to collaborate on developing common performance-based interim assessments (Stiggins, 2009). Such assessments allow teachers to combine and compare data across classrooms and work together to develop appropriate instructional responses. Utilizing formative assessments has a significant positive effect on student learning (DuFour, DuFour, \& Eaker, 2008; Stiggins, 2009).

The second main assessment type is a summative assessment. Large-scale summative assessments may be useful for ranking and comparing schools, districts, or programs. Based on 
the results, schools may have the opportunity to adjust future programming. However, these standardized assessment measures have proven an ineffective means in addressing students' current academic needs (Stiggins, 2009).

The final theoretical prong on which this study relies is Mindset Theory. Leading researcher in the field of teacher expectations on children, Carol Dweck (2006) argues that people can have a 'fixed' or 'growth' mindset. People with a fixed mindset believe that a person's basic abilities are constant and determined when born. Under this implicit theory, one's ability is set in stone, thus rendering an individual helpless in improving who he/she is. This eliminates the need or desire to practice in an attempt to develop one's skill. Individuals with this mindset seek feedback that justifies success that it serves his/her underlying ability. Rather than utilize feedback in an effort to learn, those with fixed mindsets avoid failure, as it unveils limits they envision impossible to overcome. For those with a Growth Mindset, people believe effort and persistence in training can enhance one's qualities. People who have this mindset tend to invest more energy into goal setting. This implicit theory attributes success to learning.

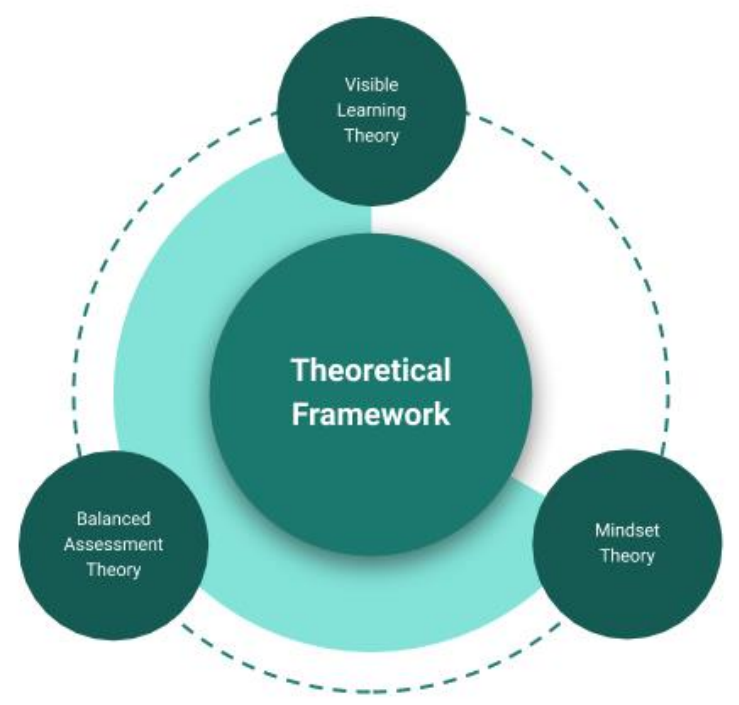

Figure 3. Theoretical Framework 
Therefore, those with a Growth Mindset view failure as an opportunity to invest effort and apply time to master a concept as they are confident in their ability to improve their performance.

Mindset Theory provides a necessary link to grading practices. The type of assessment and the way teachers grade students can foster or prohibit a Growth Mindset (Brock \& Hundley, 2016). Therefore, a potential byproduct of the grading model a district, school or individual teacher utilizes are social-emotional skills that comprise the ingredients of a Growth Mindset. For those with a Growth Mindset, failure is a chance to invest effort and time to improve performance. These theories, along with practical intervention, will provide an inquiry that unveils what works, what does not, and why.

\section{Research Questions}

SBR and Dweck's (2006) research on mindsets have embedded their way into educational research to the point they have intersected. Students with a Growth Mindset are more likely to produce more favorable outcomes, take more challenging academic courses, and persevere in pursuing academic goals (Duckworth, 2016). The question that remains is, to what extent can one impact the other?

The essence of that question shapes the two potential research questions that guide this study:

1. How has Skills Based Reporting at FMS impacted student mindset? Why do students choose or do not choose to reassess?

2. What role does parent involvement play in a student's choice to reassess? 


\section{Definition of Terms}

Traditional Grading - The practice that involves assigning a letter grade or number to a content area/course (O’Connor, 2001; Townsley, 2018).

Standards-Based Grading ( $S B G$ - — A system of assessment, grading and reporting that are based solely on student mastery linked to a specific learning standard (Schimmer, 2016; Scriffany, 2008). Used interchangeably with Competency-Based Grading.

Skills Based Reporting (SBR) —A form of competency-based grading adopted by the school in this case study focusing specifically on the acquisition of skills assessed via a non-traditional numerical system rather than letter grades.

\section{Study Design}

This study is designed to reveal the underlying reasons why students take or do not take advantage of reassessment policies. There are two primary research questions for this study which require the application of two different types of methodologies. Qualitative and quantitative methodologies will be used to complete this study. For use in the quantitative phase of the study in order to answer research question one, a student survey was administered to each student in the middle school to collect information on why they choose or do not choose to reassess. Semi-structured interviews were used to gather data from parents for the qualitative phase of this study in order to answer research question two.

\section{Positionality}

Ironically, my K-12 years as a student were spent at Farmersville. I can safely say that I took advantage of the traditional grading system. Rather than building knowledge and applying it to develop a skill, my yearning for a good grade overshadowed the development of solid metacognition. My middle-class upbringing in a predominantly white community espousing 
Judeo-Christian values brought with it the expectation that one should work hard, get good grades and treat people well. While I cherish my childhood and the guiding principles that continue to influence my life, I find it important to reflect, identify and improve upon areas of growth. For me, that centers on recognizing the value of education rather than the pursuit of grades

In a very real sense, $I$ am an extension of the community; a product of Farmersville, trying to improve its future. This research benefits Farmersville but may illuminate other factors that could shape our communities for the future. On behalf of Farmersville, I want to lead this learning expedition and take advantage of this second chance to improve learning.

\section{Summary}

In summary, a genuine problem of practice is an extension of the community and solving the problem has the potential for a sustainable impact. This research will be teeth in the gear of forward progress for Farmersville. My vision is to use this research to provide a professional development model to teachers around assessments, perseverance and Growth Mindset. That professional development will be extended to coaches of extra-curricular activities where perseverance is the key attribute to sustained excellence, as Duckworth (2016) detailed in her research. Finally, this research is intended to produce a unique audit for each Farmersville town, detailing the level of grit based on results. This audit will contribute to "community perseverance plans," which students will help construct with village leaders.

Nearly $40 \%$ of Farmersville students come from a low-income population (Illinois State Board of Education, 2019). A student's success in school impacts his or her ability to be college or career ready. Those impacts are generational, as a large percentage of graduates return to the 
Farmersville communities. If students are not interested in improving their academic status, what interest would they have in improving their community?

Chapter 1 provides an overview of the problem of practice. Chapter 2 reviewed the literature on educational assessments, including their evolution to the current standards-based trend. The design of the study and methodology were covered in Chapter 3. Chapter 4 reviewed the findings of the study, including the data-produced themes. Chapter 5 contains conclusions from the study and provides recommendations for further practice and research. 


\section{CHAPTER II: LITERATURE REVIEW}

\section{Introduction}

The Scarlet Letter made infamous by Hawthorne in his 1850 novel told the story of the adulteress who was forced to adorn a large " $\mathrm{A}$ " on her clothing to force her sin into the spotlight. The letter demonstrated outwardly and publicly the acts of the doer but fell short of telling the entire story of the woman, rendering her life a snapshot of one decision. Inconceivable in today's standards, the concept somewhat mirrors that of traditional grading practices. While represented on report cards and transcripts across the nation rather than on the students themselves, these letters are shown with pride, others with remorse and yet others with resentment, confusion and frustration. Traditional grading systems often fail to accurately reflect student learning (Guskey, 2015; Reeves 2008; 2011; Schimmer, 2016; Vatterott, 2015). Students end up chasing (or avoiding) these letters that bring with them social and academia baggage and the threats associated with stereotypes.

As accountability measures increase both businesses and colleges second-guess the legitimacy of educational attainment (O’Connor \& Wormeli, 2011). Grading is under a tremendous amount of scrutiny. Alternative forms of assessment, including SBR, have spawned from inefficiencies in the traditional grading system. Little research has been conducted on the impact SBG/alternative assessment methods has on student social-emotional skills, particularly perseverance. The purpose of this study is to help fill the void in the literature. The next section will explore the process used in exploring the research on this topic.

\section{Literature Collection Process}

The review of literature addresses traditional as well as emerging grading systems. Articles gathered for this review were generated from the EBSCO and ERIC databases. 
Standards-based grading, reporting, assessment, Growth Mindset, perseverance were descriptors used in searching the databases. Keystone authors such as Guskey, Reeves, Schimmer, Vatterott, and Wormeli surfaced consistently and are cited more frequently. The following is an outline of the literature reviewed thus far. The themes that emerged from the literature reviewed include the history of grading practices in America, the purpose of grading, traditional grading problems, SBG as best practice and the effects of SBG on mindsets.

\section{A History of Grading in "A"merica}

The meaning of grades has historically been unclear. In the 1800's students were assessed by their content knowledge and skills. Interestingly, these student progress reports were narrative, omitting any type of letter grades or symbols. As the number of schools and students began to increase, educators searched for a more efficient way to share student progress. Between 1870 and 1900 public elementary and high school districts in the United States grew from approximately 500 to around 10,000 (Marzano \& Kendall, 1996). Narrative reports of student learning became troublesome with the rise of the numbers of schools as well as class sizes. The turn of the twentieth century ushered in the traditional A-F grading method but a desire for uniformity in this metric prompted the 100-point scale to delineate between the marks (Guskey, 2015).

While several traditional practices are mainstays of school systems, federal involvement has spurred a slow, but steady shift of public education into alternate forms of assessment. In 1983, a report entitled A Nation at Risk claimed low educational expectations that produced minimum requirements were at least partially to blame for the United States' slide in science and technological advancements compared to its world competitors (National Commission on Excellence in Education, 1983). A focus on exit outcomes highlighted specific standards in 
which schools should have of each student and began what is now known as the standards movement.

\section{Purpose of Assessment}

Assessment and grading are foundational elements in educational systems everywhere, interconnected so much that it reflects the 'chicken and the egg' debate: which came first? Perhaps a more important question would be, "What's the difference?" This portion of the review will focus on the purpose of assessment, including the role that grading plays within it.

Grading and Reporting. The purpose of grading is a representation of teachers' evaluations of student performance, describing the extent to which students have achieved the learning objectives (Munoz \& Guskey, 2015). Grading is a high-leverage strategy that has the potential to improve all other elements in a school system (Reeves, 2011). Reporting is how the results of those evaluations are communicated to the student, parents, or others (Munoz \& Guskey, 2015). Grading and reporting, combined with instruction and assessment comprise a complex system that require all parts moving in alignment. Should one part be out of alignment, it impacts all other facets of the system, whether positively or negatively (Reeves, 2011). Different criteria for determining grades results in students who may achieve the same level of mastery receiving differing grades (O’Connor \& Wormeli, 2011). Done correctly, grading and reporting can have a positive effect on student achievement, motivation, discipline and attendance (Reeves, 2008; 2011). Done improperly and the opposite may occur. Education researcher John Hattie performed a meta-analysis of over 800 studies and ranked different educational interventions into effect sizes. With over 130 factors ranging from positive to negative effect sizes, Hattie found the average effect size was 0.40 , reflecting a typical year's worth of academic growth (Hattie, 2007). One attribute that shows nearly three times the 
average effect size is when students are assessment capable learners. To be assessment capable learners, students should reflect an awareness of their current level of understanding, monitor their own progress and seek feedback to help recognize that errors are opportunities to learn (Frey, Fisher, \& Hattie, 2018, p. 47). Grading and reporting should ultimately produce assessment capable learners, but another key purpose surfaces in the use of assessment and that is the use of feedback to improve student learning.

Student Feedback on Learning. All schools gather information but a commonly understood purpose behind it is more difficult to identify (Guskey, 2015). Research shows that overcoming grading challenges requires a focus on the objective (Brookhart, 2011; Guskey \& Bailey, 2010; Reeves, 2011). One such objective for assessing students in schools across the country is to provide feedback in identifying and reporting academic progress to improve outcomes (Brown, 2009; Goodwin \& Hein, 2016; Guskey, 2015; O'Conner, 2011; Schimmer, 2016; Stiggins \& DuFour, 2009; Wiliam, 2012;).

It has been shown that timely, targeted feedback is crucial to improving performance (Hattie, 2009; Wiliam, 2011; Reeves, 2011). While a grade has traditionally been considered feedback, Hattie and Timperley (2007) claim that the discrepancy between where a student is in his or her learning and where that student needs to be should be revealed in the assessment. When feedback is given effectively, "students become knowledgeable consumers of teachers' input and learn to monitor their progress (Frey, Fisher, \& Hattie, 2018, p.48). Effective feedback enhances students' awareness of their current level of understanding. Effective feedback should be purposeful and relevant in order to provide connections to the learner.

"Maximizing the potential success of each student occurs only when we pair a laser-like focus on the intended learning with formative practices that reveal the gap between where the 
student is and where he or she is going," (Schimmer, 2016, p.7). Furthermore, in order for the assessment to provide genuine feedback, the information generated must identify actionable steps to close the gap (Wiliam, 2012).

The timeliness of feedback often determines its effectiveness. Sharing results immediately or soon after the student behavior or performance is critical for changed or improved student behavior, completing the feedback loop (Wiliam, 2011). Students need an immediate opportunity to use that feedback. Whether brainstorming different ways to approach the problem or producing a plan to address future obstacles, students need to do something immediately with the feedback, otherwise it is wasted (Brookhart, 2013).

Grades should be meaningful as should the format used to report them. Grades must also be a reflection of student proficiency rather than a reward for compliance (Schimmer, 2016). Grades are wholly inaccurate and fundamentally fractured if the information they report does not reflect an accurate image of the learner (O'Conner, 2011). Even more profound, grades without feedback have been found to be counterproductive. For instance, timely, targeted feedback is shown to improve performance but when provided in tandem with numerical ratings, the information is diluted. In a study of $6^{\text {th }}$ graders, “students who got the high scores didn't need to read the comments and students who got low scores didn't want to" (Wiliam, 2011, p. 109). "It is the feedback information and interpretations from assessments, not the numbers or grades, that matter," (Hattie \& Timperley, 2007, p. 104). Feedback, rather than scores or grades, can even improve the likelihood of a positive effect. It must encourage a higher level of thinking on behalf of the learner while identifying what is next (Hattie \& Wiliam, 2011). Students are not the only group benefitting from specific feedback. Companies are encouraging employees to set stretch 
goals for themselves while receiving frequent coaching and feedback from colleagues (Duggan, 2015).

Not all assessment types generate the same type of feedback. For example, formative and summative assessments share different purposes, with only one of them designed for substantive feedback to improve learning. Information is formative when it is gathered for an instructional purpose. Formative assessment is embedded in learning and results are often used to make instructional decisions and guide learning experiences in the class while emphasizing student reflection (Brock \& Hundley, 2016). Summative assessments provide more evaluative data more beneficial for sorting students, often at the end of a unit of study. One way to delineate between the two types is to consider formative types as assessment for learning, while summative is assessment of learning (DuFour, DuFour \& Eaker, 2008).

\section{Traditional Grading Problems}

Inaccuracy_100-Point Scale. Assigning points to students for demonstrating achievement is a longstanding practice (O'Connor, 2011). Students simply accumulate as many points as possible to earn an A, B, C, D, or F. Commonly, a point based grading scale awards points throughout the semester on a scale of 0-100. Typically, an "A" ranges from 90-100, a "B" 80-89, a “C” 70-79, a "D" 60-69," and an "F" for scores 59 or below. The scores throughout the semester are averaged together for a final designation.

This system of grading is wrought with problems and is the wrong measurement to use for student proficiency (O’Connor, 2007; Reeves, 2004; Reeves, 2011; Guskey, 2015; Schimmer, 2016). The result of the percentage point scale is the identification of sixty or more levels of failure and only forty or fewer levels of passing, causing educators to determine minute levels of failure and success (Guskey, 2015). O’Connor \& Wormeli (2011) suggest “smaller 
scales with clear descriptors - such as 1.0, 2.0, 3.0, and 4.0, in which all possible scores, including 0.0 have equal skewing influence on the overall score-create a more accurate report of students' mastery" (p.41). Reviewing performance on a large scale, whether student or employee, has been proved to impact little change in behavior. Reducing or eliminating ratings altogether forces students or employees to focus on what matters, including meaningful discussion with timely feedback that result in personal growth and increased results (Goodwin \& Hein, 2016).

Another argument against a high number of performance levels is that with students trying to earn the maximum number of points so their average grade is higher, they lose sight of what those points represent (Tucker, 2018). This traditional approach misplaces student focus on earning points rather than learning.

Inaccuracy-Averaging Points. In the traditional classroom, student work over the course of a nine-week term is graded and averaged together, resulting in one letter grade that is reported out at the end of the term for each course. Assignments that are given at the beginning of the learning process carry just as much weight in the end as when students have been given an opportunity to truly learn the material and demonstrate knowledge. Essentially a completion of a series of activities, a student's understanding is not necessarily represented when averaged together as old evidence is usually combined with new evidence in an effort to accumulate points. Averaging grades between two or more scores decreases accuracy (O’Connor \& Wormeli, 2011). These scores are averaged throughout the span of a semester and sometimes one school year, all of which are reflected in a final grade. As one might expect, a student's skill proficiency changes throughout the semester based on a variety of factors as the class makes their way through the standards embedded in the content. A student who makes dramatic 
improvements in his/her learning over the semester may not be reflected in the final grade, as the work produced early in the learning process is weighted along with the most current performance.

Individual assessment scores should be a reflection of student learning at one particular point in time. Should the objective be for students to master the skills by the end of a school year, the timing of when the student reached mastery should not negatively impact a student's grade if reached within that school year. If a student receives a poor grade on one assignment only to improve the grade on a later assignment on the same topic, the earlier performance is not indicative of the student's skill level (O’Connor \& Wormeli, 2011). Teachers combine scores from exams, quizzes, projects, reports, homework, class participation as well as non-academic factors such as work ethic and compliance (Guskey, 2015; Munoz \& Guskey, 2015; Reeves, 2004). Furthermore, that anecdotal information is typically combined in idiosyncratic ways. Teachers produce anecdotal comments and various symbols void of commonality and mutually understood terms for students and parents to navigate (McMillan, Myran, \& Workman, 2002). The resulting grade presents an incredible challenge to interpret and leaves meaning as an afterthought. It is suggested that teachers avoid this conglomeration grade where a single mark represents multiple products (O’Conner, 2011).

Homework is a strategy long used in education to ensure students are practicing the academic skills learned in school. A disconnect occurs when practice is included in a final grade (Scriffany, 2008). "Grades are broken when evidence of learning from multiple sources is blended into a single grade and the communication fails to show how successful students have been in mastering individual standards/learning goals," (O'Connor, 2011, p.58). The same is true of issuing extra credit to students. Research has shown (Jung \& Guskey, 2012; O’Connor \& 
Wormeli, 2011) students who are struggling with learning targets are those who are least likely to take advantage of extra credit opportunities. Yet, extra credit is one of many factors used in determining student proficiency. This type of practice led Marzano (2000) to point out that "Grades are so imprecise that they are almost meaningless" (p.1).

Another consequence of using averaging in a grading model is the student despair that sets in the last two months in a semester, leading to an increase in discipline problems (Reeves, 2011). Crushing student creativity is another unintended consequence of this approach to grading. Opportunities abound for fostering creative thinking because learning a generative act (Brookhart, 2013). However, the traditional model of assigning tasks to accumulate and average points overshadows the fostering of creativity. Students complete worksheets and other 'drill and kill' approaches such as rote memorization and recitation to capture as many points as possible before forgetting the information after the exam, as the reward for learning was the grade earned on the exam. These uncreative and lower rigor assignments also prevent the level of quality feedback required for student growth as teacher can give more complex feedback on more complex assignments (Brookhart, 2013). Work given to students should be intentional and designed to hone specific skills and produce feedback specific to student growth. When teachers ascribe one-size-fits-all assignments, however, it creates frustration and discouragement on behalf of students who see the task as repetitive or unnecessary (Tucker, 2018). Just as feedback should be tailored to individuals, assignments should be as well.

Inaccuracy--Grading as Punishment, Zeroes. The threat of using grading as punishment is another attribute that has rendered the traditional grading model toxic (Reeves, 2011). Critics of emerging grading systems warned that without holding grades over students' heads as a threat of punishment, no incentive would exist for students to attend school, no less 
perform well. Other teachers fear an inaccurate view of the real world will result, as will a loss of student responsibility if students are not penalized via gradebook. Reeves (2011) reports that after exhaustive trips across the world, "perhaps it's time to stop focusing so much on grading as punishment, which has not worked for a century, and refocus our energies on creating incentives for work that students do correctly and on time" (p.78).

A traditional grading system also overemphasizes a 0 in the gradebook when determining a final grade. Under a grading scale where a $94 \%$ is an A, a student must earn 9 straight $100 \%$ 's in order to overcome a single 0 and move their grade to a B. A zero on a 100-point scale is the mathematical equivalent to a -6 on a 4.0 scale, illustrating that a student would need to climb six levels in order to get even with what could be considered absolute failure (Reeves, 2004). Even though they have demonstrated perfection nine times in a row, according to the gradebook, that student has only achieved the second highest level of achievement. Students in this scenario are unable to retake the exam or assignment. Using zeros to measure student proficiency is an inaccurate and unfair system that violates the boundaries of effective grading policies (Reeves, 2011). Not only does a zero falsify the report, but immediately generates despair for the student (O’Connor \& Wormeli, 2011).

Teachers enter dozens upon dozens of assignments in the traditional gradebook, ranging from math homework, bringing appropriate materials to class and participating in class discussions. Students are assigned a respective, yet subjective amount of points for their performance on each, resulting in a grade that reflects organization or motivation than of the student's academic skill level (Tucker, 2018). Furthermore, there are many students who earn high grades but perform very poorly on standardized testing (Marzano, 2010). These are the students who generally have the more difficult transition to SBG. With SBG, the students who 
work hard do not necessarily earn the highest score whereas the traditional grading model rewards students who worked hard, completed assignments, yet do not demonstrate mastery (Tucker, 2018). On the other hand, students can perform well on standardized assessments but be graded poorly in school (Wormeli, 2011). This is largely attributed to grading based on compliance. Schimmer (2016) reported that grades must be a reflection of student proficiency, rather than rewards for compliance, yet students are generally punished via grades due to obedience related issues (O'Connor, 2011). The result is a biased view of reporting that unfairly benefits females (Reeves, 2011). More importantly, it's an inadequate representation of performance for all involved.

From Traditional to Emerging...

Traditional grading models have been around for over a century, yet no meaningful research supports it (Marzano, 2000). We have arrived at a point in time with grading practices where we find ourselves doing things simply because it has been past practice. Teachers and parents have a tendency to default to the strategies they experienced in school (Reeves, 2004). However, past practice is not always best practice. Stiggins (2005) stated the industrial model of education used for over 100 years formed the basis of the grading system still in place current day.

Today's adults grew up in school designed to sort us into the various segments of our social and economic system. The amount of time available to learn was fixed: one year per grade. The amount learned by the end of that time was free to vary; some of us learned a great deal as previous grades continued to build on those foundations. Those who had failed to master the early prerequisites within the allotted time failed to learn that which followed. (p. 234) 
The traditional A-F grading system is such a staple in our society that it's used in noneducational contexts such as when grading politicians or road quality (Schimmer, 2016). Altering an accepted method so ingrained in the profession as well as society creates a second-order change and presents a tremendous challenge. A second-order change involves disrupting and transforming a concept that challenges assumptions (Bartunek \& Moch, 1987). Furthermore, grading practices is an emotional and often personal topic that can produce a deep philosophical divide.

Despite the friction second-order changes may create, following the research in making sound decisions for our students is necessary (Marzano, 2000; Guskey, 2015; O’Connor \& Wormeli, 2011). The gap between current and desired states of student learning will linger should intentional change in grading and reporting practices be initiated, executed and reflected upon. Rather than a criticism of the past, grading reforms should be thought more so as optimism for the future (Reeves, 2011). The grading experts of today (O'Connor, 2009; Reeves, 2011; Guskey, 2014; Guskey, 2015; Schimmer, 2016; Wormeli, 2011; Vatterott, 2015) agree that grading practices be refreshed to better reflect how students are learning.

How students are learning is not the only shift occurring in education that supports the transition to SBG. The impetus of college, career and life readiness to match the changing technology needs and evolving workforce has thrust education beyond the traditional model of instruction and assessment (American Association of School Administrators, 2019; World Economic Forum, 2016). Rapid technological advancements have transformed the skills needed to prepare students for post-secondary opportunities, including the need for crucial social skills including critical thinking, Growth Mindset, collaboration, problem solving, creativity, adaptive thinking and cognitive flexibility (American Association of School Administrators, 2019; Center 
for Community College Student Engagement, 2019; Colvin, 2015; Tough, 2012). Another shift is the personalization of education. When traditional grading practices were introduced, educators were teaching the masses with little emphasis on differentiation (Guskey, 2015). Expectations and accountability measures have evolved for each student to graduate with an individualized learning plan aligned to a college-career pathway (CSM Learn, 2019). All of the aforementioned shifts support the adoption of SBG. What follows is a more in-depth examination of SBG as best practice.

\section{Standard Based Grading and Reporting as Best Practice}

Accuracy in Determining Student Learning. Standards-Based Grading operates under three basic principles: 1) Grades have meaning; 2) Students have multiple opportunities to demonstrate learning based on feedback; 3) Only current academic performance towards specific learning targets is graded (Townsley \& Buckmiller, 2016). Timely, targeted feedback is crucial to improving performance (Hattie, 2009; Wiliam, 2011; Reeves, 2011) and accurately identifying student learning is the result of SBG.

Grades Have Meaning. There are several ways in which SBG is improved from traditional grading models. First, SBG incorporates fewer performance level descriptors as opposed to traditional grading methods. Fewer performance levels result in grades that provide more meaning as other aspects of student performance are not included in a students' summary of achievement but reported in a category separate of academic achievement (Munoz \& Guskey, 2015).

Feedback is crucial for improving student performance and grading is one of the avenues feedback is provided (Reeves, 2011). Improving the accuracy of grading and reporting, SBG is based on a sufficient body of evidence. Assessments are provided in a clear, timely, accurate and 
useful manner. Report cards help communicate a students' progress in specific skill strands within a content area, identifying students' strengths and areas for growth. More importantly, they inform instructional decisions including future class selection or placement (Munoz \& Guskey, 2015). Using a standards-based report card also provides educators the ability to provide more detailed information to parents while avoiding an unnecessary emotional battle concerning grades (Reeves, 2011).

When the most recent assessment scores are reflected, a more accurate picture of a student's true ability is captured. This provides a powerful incentive for students to perform their best work on each assessment (Tucker, 2018). SBG provides students more voice, or ownership in his/her learning. Should a student disagree with a teacher's discernment of his/her level of proficiency, SBG enables students to present evidence of learning to the teacher to support their claims. This opportunity to articulate their growth as learners results in grades becoming an ongoing dialog instead of something that passively happens to the student (Tucker, 2018).

SBG more practically emphasizes continued learning. If followed properly, SBG will shift the focus to quality of learning from the current infatuation of the accumulation of points (Guskey, 2015; Reeves, 2004; Tucker, 2018). Students who understand the "why" of grading will more likely obtain an intrinsic love of learning while seeing the value of their work (Tucker, 2018). In short, SBG enables students to earn an education rather than a grade.

Students Have Multiple Opportunities to Demonstrate Learning. Schools no longer take the approach of simply failing students who don't learn (Vatterott, 2015). Rather than sorting talent, schools find themselves responsible for developing it (Guskey, 2011). Developing skills within students necessitate grading practices like SBG. Assessments should encourage 
students to keep trying, whatever their level of achievement (Curwin, 2014). Therefore, there is no place for zeros in SBG.

Students learn at different rates. Rather than blaming students when learning doesn't happen on schedule, schools should be quick to allow students additional chances at assessments. "Curriculum goals don't require that every individual reaches the same level of proficiency on the same day, only that every student achieves the goal" (Wormeli, 2011, p.23). SBG allows students to work towards mastery beyond the initial class assessment (Townsley, 2018). Regardless of the time it took each student to provide evidence of the learning, SBG enables teachers to accurately assess student proficiency. A driver's licenses is still issued after multiple tries, surgeons take advantage of practicing on cadavers (Wormeli, 2011) and authors endure multiple rewrites and editing sessions before a final draft. Should school offer an authentic representation of the real world, then multiple chances at assessments for full credit should be the norm (Townsley, 2018). Grading students on where they finish in regards to learning standards, rather than where they started makes sense. Despite the evidence supporting continuous chances of showing mastery, a common-held practice of traditional grading models is to expect students to learn content as if on a conveyor belt; that is, "if you don't get the content, you take the low grade and move on" (Wormeli, 2011, p.24).

One of the main principles of SBG is to incorporate multiple opportunities for students to demonstrate mastery based on teacher feedback. Retakes, or "redos" (Wormeli, 2011), while avoided in traditional grading methods, are embraced in SBG. Since the purpose of grading is to capture the extent of student mastery towards learning targets, educators should look for evidence of learning over time (Marzano \& Heflebower, 2011). Implementing redos as a grading strategy is often necessary if capturing accurate and timely student understanding instead of a 
moment in the past. Evidencing this was a comprehensive review of classroom instructional strategies by Haystead and Marzano (2009) which revealed a 34 percentage point gain when tracking student progress towards a learning goal over time as compared to one summative snapshot. Teachers who wish to build students' character or "moral fiber" (Wormeli, 2011) may deny the opportunity for retakes or give only partial credit for redone assignment, regardless of the level of mastery evidenced. A true consequence for students avoiding school work is not a zero, but actually completing the work (Reeves, 2008).

Grades Are Based on Academic Performance Only. Effectiveness of grades comes when academic achievement is the only component reflected. Rather than an accumulation of points from averaging together completed activities, SBG reflects student achievement towards specific standards over times. This more accurate reports what students truly know, while providing higher correlations with student testing done outside of school (Marzano, 2000; Reeves, 2011). There is still a place for homework in an SBG model. However, homework is recognized as practice within an SBG approach and thus students' final grades are not impacted by it. Students are not penalized with a grade for imperfect practice nor rewarded for trying with a grade for practicing harder. Townsley (2018) provides a sports analogy to the idea of assigning a grade based on homework, saying the scoreboard does not reflect extra practice prior to the beginning of each game.

"In the same manner, students should not be penalized for practicing their learning poorly. Instead of assigning a point value for completed or accurate homework, we report symbols in the gradebook documenting completion in the gradebook with such notations as collected, missing, late or absent. This information allows parents and students to view the level of practice being completed while focusing on the numbers entered in the gradebook that describe the student's current level of understanding relative to course standards" (p.17). 
SBG removes any portion of a student's score that measures something beyond academic capacity (Marzano, 2000). A feedback tool based on the standards guides the teachers' lessons and aligns curriculum to the course goals, allowing only the necessary content to be assessed (Vatterott, 2015). SBG eliminates the guesswork in interpreting the omnibus grade which was comprised of a mixture of multiple forms of activities averaged together throughout the semester, including non-academic skills. Non-academic skills can still be valued in an SBG approach and even reported. However, these skills, such as work habits, study skills, citizenship, etc., are reported in another section. Furthermore, the section should include descriptions or comments to improve the preciseness of the grade (Munoz \& Guskey, 2015). Approaches to SBG require teachers to use explicit criteria to base grades from the articulation of learning standards. The meaning of each standard is analyzed by teachers including what evidence best reflects achievement for that standard (Guskey, Swan \& Jung, 2011). Specifying the evidence for achieving the standard has been proven effective in determining accurate performance (Munoz \& Guskey, 2015).

Students are more than a composite of their digressions and successes. Assessments that are graded and reported correctly have been a positive and powerful tool that informs instruction and improves student learning (Munoz \& Guskey, 2015; Vatterott, 2015; Schimmer, 2016). Standards-Based Grading does not allow for inaccurate, hodgepodge grading of traditional methods that take into account various non-academic factors when determining grades. Rather, only specific feedback of a student's progress towards specific learning targets are reported in SBG (Reeves, 2011; Guskey, 2015; Schimmer, 2016).

Teachers must decide what evidence best serves the reporting of student learning, thus a tremendous amount of discretion is needed. While grading can be seen as the "last frontier of 
individual teacher discretion" (Reeves, 2008, p. 86), a temptation still exists for teachers to use the plethora of graphs, averages and other evidence and let the computer spit out a grade (Schimmer, 2016). However, SBG allows for a large amount of professional judgment (O'Connor, 2009). The traditional grading model embraces the calculation of points but SBG makes room for the art of grading. "The art of grading is to use the numbers, but not let them be the final judge," (Schimmer, 2016, p.52).

\section{Standards Based Grading Effect on Mindsets}

SBG and Dweck's (2007) research on mindsets have embedded their way into educational research to the point they have intersected. The previous sections of this review highlights the favorable results of emerging grading methods, specifically SBG. Students with a Growth Mindset are more likely to produce more favorable outcomes, take more challenging academic courses and persevere in pursuing academic goals (Duckworth, 2016). The question that remains is, to what extent can one impact the other? The essence of that question shaped the two main research questions that guide the purpose of this study:

1. How has Skills Based Reporting at FMS impacted student mindset? Why do students choose or do not choose to reassess?

2. What role does parent involvement play in students' choice to reassess?

Educational motivation has been defined as the desire to learn (Curwin, 2014) and is considered the catalyst for learning (Frey, Fisher \& Hattie, 2018). A strong and positive climate provides the foundation for authentic learning to occur. Lessons are designed with relevance to leverage student interest. Students must take an inventory of their own learning and self-assess their work in pursuit of their goals. 
An important factor for students to be assessment capable learners, which can lead to enormous academic gains, is for students to seek feedback and recognize that errors are opportunities to learn (Frey, Fisher \& Hattie, 2018). Mistakes made over the course of the semester should not be considered failures but learned lessons on the way to success (Reeves, 2008).

When learning is constructed in which students actively seek answers to meaningful questions rather than passive receivers of knowledge, a Growth Mindset is cultivated. The absence of this is considered a crisis of significance (Brock \& Hundley, 2016). "Grading is as emotional as it is clinical for students... assessment must be one that nurtures the Growth Mindset," (Schimmer, 2016, p. 25). Assessment can do a number on a student's Growth Mindset. If students are given the opportunity to retake assessments, a growth-oriented culture is sowed. When teachers design environments that celebrate Growth Mindsets, students will desire the retake of assessments and won't settle with not doing well. Students are willing to produce great effort if they understand that progress is the goal (Brock \& Hundley, 2016).

Performance ratings have a tendency to affirm a fixed mindset should the one being evaluated internalize the information and consider it a permanent flaw (Dweck, 2006). Students must know there is a path to recovery. Brock and Hundley (2016) argue that motivation can change when students realize they can retake exams, stating, "grading is fine, but the student should always have a chance to increase their score" (p.163). Reduced discipline problems, a reduction in the number of failures, improved teacher morale and an increase in college credits are all benefits of effectively implementing Standards-Based Grading (Reeves, 2011).

Extrinsic rewards can discourage the very behaviors they were originally intended to encourage. Using grades as external incentives can decrease motivation (Guskey, 2011) as well 
as lead to diminished performance, addictive behaviors and even cheating (Mathis, 2010). Rewarding enjoyable activities turns into a mandate. Furthermore, this leaves students to recognize that they are being rewarded for complying with a knowingly boring and tedious assignment. Brookhart (2009) finds that risk-taking decreases when everything is counted as a grade. Students will pursue safe tasks rather than risk imperfections and ultimately a grade point average. This is where teachers can organize assessments in a way to support a Growth Mindset. For example, rather than percentages or scores, teachers and students can focus on tracking progress toward mastery on specific targets through recognition of what type of remediation or practice is needed (Brock \& Hundley, 2016).

Stiggins (2005) found that some students grasp concepts very quickly and score well on assessments which improves confidence and motivation. This success invites the desire for more academic success. Pink (2009) found that student motivation correlated with academic performance. For example, if a student experienced good grades, his/her motivation improved. Rather than reinforcing fixed mindsets in relation to ability levels, assessments should produce a score that teachers report as constantly developing attributes. "If you're going to be a good teacher, you have to believe in malleable intelligence" (Tough, 2012, p.98) and for students to demonstrate grit, they must believe in their ability to improve their learning (Duckworth, 2016).

Valuing and focusing attention on talent with the labeling of grades inadvertently sends a message to students that grit matters little in learning. However, the opposite is true. Employers desire employees who are hardworking and demonstrate grit five times more than they desire intelligence (Duckworth, 2016). An economic development council sent a survey to over 150 area businesses seeking the skills in which they value of incoming employees. Additionally, employees identified which skills were most prevalent and which skills were lacking. On a scale 
of 1-5 with one being not important and five being most important, perseverance ranked near the top in terms of importance. However, employees identified the actual performance of that skill by employees to be significantly lower than desired (Bloomington-Normal Advantage, April 2018).

\section{Theoretical Framework}

Merriam (2009) describes a theoretical framework as underlying all research and more specifically "the underlying structure, the scaffolding, or the frame of your study" (p.66). Qualitative research is inductive in nature, thus making it more difficult in identifying a theoretical framework (Merriam, 2009). Merriam (2009) suggests that the researcher draw upon the "concepts, terms, definitions, models and theories of a particular literature base" as doing so will generate the problem of the study and help interpret the findings (p.67). This study will draw upon two theories. The first theory contributing to this framework includes the Balanced Assessment Theory.

Balanced assessment is an assessment strategy that recognizes no single assessment yields the comprehensive results necessary to inform and improve practice and foster school and system accountability; therefore, balanced assessments utilize multiple measures of student achievement including formative assessments for learning and summative assessments of learning. Balanced assessment also refers to using different types of formative assessments based upon the knowledge and/or skills students are called upon to demonstrate. Rather than relying exclusively on one kind of assessment, schools and teams develop multiple ways for students to demonstrate proficiency (DuFour, DuFour, \& Eaker, 2008, p.463) 
Teachers implement formative assessments during an instructional unit on a frequent basis to assess student learning in real time. Used effectively, formative assessment provides information that helps the teacher adjust instruction to improve learning. Interim assessments take place in time for teachers to adjust instruction to address any identified gaps in student mastery (DuFour, DuFour, \& Eaker, 2008). However, researchers have found that a more effective approach is for teachers within a school to collaborate on developing common performance-based interim assessments (Stiggins \& DuFour, 2009). Such assessments allow teachers to combine and compare data across classrooms and work together to develop appropriate instructional responses. Utilizing formative assessments has a significant positive effect on student learning (Heritage, 2007; DuFour, DuFour, \& Eaker, 2008; Stiggins \& DuFour, 2009).

Large-scale summative assessments may be useful for ranking and comparing schools, districts, or programs. Based on the results, schools may have the opportunity to adjust future programming. However, these standardized assessment measures have proven an ineffective means in addressing students' current academic needs (Stiggins \& DuFour, 2009).

The other theoretical prong with which this study relies is Mindset Theory. Leading researcher in the field of teacher expectations on children, Carol Dweck (2007) argues that people can have a 'fixed' or 'growth' mindset. People with a Fixed Mindset believe that a person's basic abilities are constant and determined when born. Under this implicit theory, one's ability is set in stone, thus rendering an individual helpless in improving who he/she is. This eliminates the need or desire to practice in an attempt to develop one's skill. Individuals with this mindset seek feedback that justifies success that it serves his/her underlying ability. Rather than utilize feedback in an effort to learn, those with fixed mindsets avoid failure, as it unveils limits 
they envision impossible to overcome. For those with a Growth Mindset, people believe effort and persistence in training can enhance one's qualities. People with a Growth Mindset tend to invest more energy into goal setting. This implicit theory attributes success to learning.

Therefore, those with a Growth Mindset view failure as an opportunity to invest effort and apply time to master a concept as they are confident in their ability to improve their performance.

Mindset Theory provides a necessary link to grading practices. The type of assessment and the manner in which teachers grade them can foster or prohibit a Growth Mindset (Brock \& Hundley, 2016). Therefore, a potential byproduct of the grading model a district, school or individual teacher utilizes are social-emotional skills that comprise the ingredients of a Growth Mindset. To what extent SBG impacts student perseverance is one question this study intends to answer. But first, the themes unveiled from the literature review will be detailed.

\section{Summary}

Grading reforms have articulated and emphasized learning standards while tying results to accountability (Reeves, 2011). Grading and reporting, however, remain untethered to the reforms, with traditional grading models still permeating the educational landscape. Existing literature suggests that SBG is a student-centered approach that can produce assessment-capable learners, ultimately enabling productive feedback to improve learning. Creative methods in assigning and evaluating student work has the potential for learning to enter back into the spotlight. When students and teachers recognize their strengths and understand areas for growth, grades become an avenue for the evolution of learning.

This evidence highlights the necessity for further examination from the student's perspective of SBG's impact on perseverance in the pursuit of learning. Information provided from this most crucial component will assist in the execution of the competency-based education 
model for the school under study. Finally, this research will assist in ensuring students' learning is an accurate reflection of composite factors rather than being reduced to a mere letter. The following chapter will provide an overview of the design and methods used for the study. Included in the methods section will be qualitative and quantitative techniques, data collection and analysis, instrumentation, ethical considerations and limitations of the study. 


\section{CHAPTER III: METHODOLOGY}

In this chapter, the research design and methodology of the study are described. The purpose of the study, research design, instrumentation, data analysis, ethical considerations, trustworthiness and limitations of the study are expanded upon to give a comprehensive overview of the research methodology.

\section{Purpose of the Study}

The purpose of this study was to investigate the factors behind whether students choose to reassess or not to reassess. In addition, this study seeks to find how parent involvement impacts student reassessment. The data for the study was collected from two sources: quantitative data from students using survey questions and qualitative data from parents via interviews. This study aims to answer the following questions:

1. How has Skills Based Reporting at Farmersville Middle School impacted student mindset? Why do students choose or do not choose to reassess?

2. What role does parent involvement play in a students' choice to reassess?

\section{Research Design}

In this study I explore the perceptions of students and parents from one rural Midwestern middle school on how the school's skills-based reporting initiative has impacted student mindset. In this research, I employ a convergent parallel mixed-methods design. Mixed methods is a relatively new approach to research in the social and human sciences, originating around the late 1980's and has since expanded into many different disciplines (Teddlie \& Tashakkori, 2009). The benefit of employing both qualitative and quantitative designs is simply to overcome the limitation of one design (Creswell, 2012). More specifically, mixed methods enables the exploration of this phenomenon from multiple perspectives. The convergent mixed methods 
approach includes the separate collection, analysis and comparison of both quantitative and qualitative data (Creswell, 2014). In this study, the quantitative data used consisted of a survey administered to students to determine if and how Skills Based Reporting at FMS has impacted student mindset and to determine why students choose or do not choose to reassess. Qualitative data was derived from semi-structured interviews conducted with parents in an effort to uncover the role that parent involvement plays in students' choice to reassess.

Merriam (2009) states that "the overall purposes of qualitative research are to achieve an understanding of how people make sense out of their lives, delineate the process (rather than the outcome or product) of meaning-making, and describe how people interpret what they experience" (p.14). Because this research was seeking to understand parents' thoughts on student mindset and reassessment, qualitative methods were appropriate. A basic supposition of qualitative research is people constructing reality by living and working in their surroundings (Merriam, 2009). Creswell (2012) also supports the notion of qualitative methodology in the educational context as the researcher is dependent upon the contextual understanding of a participant in a particular environment. Understanding a specific phenomenon from an emic, or insider's perspective serves as an invaluable component to qualitative research (Merriam, 2009).

Caudle (2004) states, "the power of qualitative research comes in large part from the ability to move between, explore, and enhance the design, data analysis, and findings as the study proceeds" (p.417). Merriam (2009) explains the task of a phenomenologist is to "depict the essence or basic structure of experience" (p.25).

The research questions are more likely to be answered with data that is derived from a variety of sources; in this case descriptive research via student surveys and parent interviews. Vogt, Gardner, and Haeffele (2012) provide six main reasons that justify combining research 
designs, with one reason being when the researcher desires to tell the full story in an area of inquiry. Such is the case with this problem of practice.

\section{Participants and Research}

The site of this study has a district enrollment of approximately 2,000 students with 405 enrolled in the middle school at the time the study was conducted. The middle school in which the research was conducted has been implementing a component of competency-based learning called Skills Based Reporting for the past three years. Over the course of those three years, the school's nearly 40 certified teachers have received training on Standards Based Grading, Competency-Based learning and other components of student-driven education.

Participants in this study included all sixth, seventh and eighth grade students. These students completed an anonymous, online survey regarding their reassessment practices and general thoughts on perseverance, reassessment and mindset. The number of student participants numbered 384, leaving 21 students who did not participate due to absence or cognitive ability. The student-completed surveys consisted of 17 questions that were analyzed quantitatively. The final question of the student survey consisted of an open-ended question that participants responded via short answer. The open-ended question was analyzed qualitatively. The student survey results contributed to answering this study's first research question, "How has Skills Based Reporting impacted student mindset?"

All parents with students at FMS were invited via email to participate in interviews to share their experiences and thoughts behind Skills Based Reporting, reassessment policies and mindset. Seventeen parents expressed interest in participating. Each of those seventeen parents were interviewed. The results provided rich qualitative data that helped answer the research question, "What role does parent involvement play in reassessment?" 


\section{Instrumentation}

After performing an extensive review of the literature on skills-based reporting as well as the role of a student's mindset in academic achievement, themes generated from the literature review were used to construct a student survey and parent interview questions with the hope that data gathered with these tools will provide answers to the research questions posed in the study. Each student enrolled at FMS was invited to participate in the student survey. In order for students to participate, parent permission was obtained in the form of a parent assent form (Appendix C). Parents who chose not to allow their children to participate were to return the form. Otherwise, no further action was needed for parents who had no objection with their child participating in the survey. A three-week window was provided for parents to deny their child's participation. Prior to beginning the student survey, students provided their assent (Appendix D) by reading a brief paragraph outlining the purpose of the survey written in student-friendly language.

Questions 1-6 in the student survey questions (see appendix C) provided demographic information from the students, including gender, town of residence, whether students took an advanced placement class, participated on a team, how many times they had reassessed that semester and in which subject they reassessed the most. While certain demographic information such as gender was identified as part of the instrumentation, stratification did not occur in the selection of participants. Other questions solicited subjective type of information including the students' perception of his/her Growth Mindset, perseverance and their perception of correcting assessments for an improved score. Finally, one question remained open ended and provided students the opportunity to provide a short response to the probe, "I would reassess more often if...". The final survey consisted of 15 closed-ended questions and one extended response. 
A Likert scale was used for subjects to rate their level of agreement to questions about reassessment in school. The Likert scale response choices included, 'strongly agree,' 'agree,' 'undecided,' 'disagree' and 'strongly disagree. Following the specific questions pertaining to reassessment, participants were asked to complete similar Likert scales to questions based on grit. Finally, participants were asked a series of questions rating their perception on the possibility they can change certain factors including 'being talented,' 'giving a lot of effort,' and 'your level of intelligence.' These growth-mindset-themed questions used Likert scale choices of 'completely possible to change, quite possible to change, somewhat possible to change, a little possible to change, not at all possible to change.' The exhaustive list of student survey questions can be found in Appendix C. Survey items were checked for content validity by a distinguished methodologist. Qualtrics was the online survey product used to create and send the survey as well as collect the participant's responses.

\section{Data Collection}

The study will consist of two different avenues of data collection. First, student participants will be invited to complete a survey designed to generate the students' perception of his/her Growth Mindset, perseverance and their perception of correcting assessments for an improved score. Surveys are useful when gathering information to describe characteristics of a large population (Creswell, 2014). The student survey was administered by certified teachers in classrooms to each student enrolled in the middle school.

Interviews were conducted with parents who had a child attending the school. Interview questions sought to identify parent perceptions on student mindset and reassessment opportunities at school. Participants were interviewed separately utilizing a semi-structured interview protocol (See Appendix D). Each of the interviews lasted 30-65 minutes. Open-ended 
questions allowed for flexibility in responses, allowing participants to more authentically give their perceptions (Merriam, 2009). Interviews were audio recorded to preserve accuracy and meaning. Field notes were taken before and after the interviews, including reflections of participant's mannerisms and behavior as well as my thoughts.

Once the participants were selected, they were interviewed using a semi-structured interview format. For this study, an interview protocol, or list of questions was prepared (see Appendix B). Depending on the responses of the participants, different probes were utilized for follow up questions to generate more specific information. Probing includes asking for more detail or clarification and may lead to a clearer understanding of the participant's viewpoint (Glesne, 2006).

Special care was taken in developing the wording of interview probes. Merriam (2009), Creswell (2008), and Dilley (2000) emphasized the need for good interview questions, providing guidelines from which to develop wording of questions. The probes remained open-ended, allowing for flexible responses from the participants and providing a variety of follow-up possibilities from the researcher. The interviewer is advised to reflect on the interviews conducted as a means of improving one's practice and generating more productive data (Dilley, 2000). This reflection occurred both during and after each interview for this research study.

\section{Data Analysis}

Data analysis was conducted in two phases to match the mixed method research approach. First, quantitative analysis will be reviewed followed by the quantitative analysis.

\section{Quantitative}

Descriptive statistics were used to organize, summarize and describe how student participants responded. Likert scale items assisted in classifying data into ranked categories 
(Creswell, 2014). The ranked categories measuring student perceptions on Growth Mindset values and level of perseverance were designed to find trends relating to other student factors, including the towns in which they reside, advanced placement classes in which they were enrolled and whether or not the student participated in an extracurricular activity. Data gathered from the student surveys was transferred into statistical software (SPSS) for analysis. Descriptive statistics, defined by Vogt, Vogt, Gardner, \& Haeffele (2014) as "methods used to portray the cases in a collection of data, to depict patterns in the data, to explore the distributions or shapes of the data, and/or to summarize the basic features of the data" (p. 207) was used to analyze the data. Descriptive analysis included means, standard deviations, range of scores and percentages. An aggregate of the results will be presented in the results section.

\section{Qualitative}

Once the transcripts were completed, the data from the interviews were coded.

Transcripts were coded using thematic analysis. Thematic analysis is a method for systematically identifying, organizing, and offering insight into patterns of meaning across a data set (Clarke \& Braun, 2013). This method is designed to make sense of commonalities. Transcripts were coded by hand to identify commonalities among responses, by research question and individual probes (Merriam, 2009). First, the transcripts were read carefully so the researcher could get a sense of the whole picture. Then, one interview was read at a time with topics being identified within the columns. Topics were abbreviated into codes. Codes were then consolidated into similar themes to reduce categories. This was done over three separate readings, or waves, of the transcripts.

Throughout the process, the research questions were kept at the center of the data analysis. Caudle (2004) describes, "The research questions keep the analyst tethered to the main goal" (p.436-437). These themes were presented in the results and conclusions portion of this 
study. The open-ended survey prompt was crucial in allowing students to summarize their feelings concerning reassessments. Those answers were coded to convert words into values that allowed trends to appear from the data (Creswell, 2014).

\section{Ethical Considerations}

"In qualitative studies, ethical dilemmas are likely to emerge with regard to the collection of data and in the dissemination of findings (Merriam, 2009, p.250). Before beginning the interview, participants were provided an informed consent letter detailing the research overview and providing contact information of the researcher for the participants. Extra copies of the consent forms were made available for the participants for their reference. Participants were informed that their participation was voluntary, and they could choose not to participate or withdrawal at any time without repercussion. Participants selected the location for the interview which helped preserve confidentiality. In this study the interview participants were assured confidentiality with the utilization of pseudonyms. Students were assured anonymity as no personal identifiable information was collected via the survey. Interview participants were informed of their ability to refuse any question at any time or request to be removed from the research study at any time without repercussion. Special attention was given to ensure the participants' data was gathered and interpreted correctly. Additionally, I performed member checks to ensure all voices were heard correctly and to protect validity. Interviews were audio recorded and field notes transcribed immediately.

The research took place at a location convenient to each participant. In an attempt to maintain confidentiality, the research was conducted in a location that provided privacy for the participant. The study's participants were recruited via a standard recruitment letter (Appendix

A) that was sent digitally to all guardians with a student that attended the middle school. An 
informed consent letter (Appendix B) was included in an email along with the recruitment letter. Furthermore, the informed consent letter was signed by each participant with the researcher as an eyewitness before the interview commenced. Extra copies of the forms were available for participants for their reference.

The research presented no more than minimal risk of harm to subjects. While participants were assured anonymity, some may have felt pressured to manipulate their responses to support the perceived hypothesis of the principal investigator. Research participants were informed they could refuse any question at any time or request to be removed from the research study at any time without repercussions. Special attention was given to ensure the participants' data was gathered and interpreted correctly.

Prior to the student participants beginning the online anonymous survey, a brief cover letter describing the research was viewed by the students. Participants selected the option to begin the survey, signaling their voluntary participation. Furthermore, there was no compensation offered to any participant, whether parents or students. All participation was voluntary and non-coercive. Upon approval by the Institutional Review Board, which included the required approval from the participating school district, the recruitment process began.

\section{Trustworthiness, Authenticity and Credibility}

Member checking was used in the study, highlighting the meticulous nature and attention to accuracy. Each participant received a transcript of his or her interview, allowing the participant an opportunity to spot inaccuracies, clarify meaning or add information. Validity of collected data was maintained throughout the collection process. Interviews were transcribed verbatim, immediately following the interviews. As recommended by Dilley (2000) and Merriam 
(2009), observations from the interview were recorded along with the mannerisms and behavior of the participants. There were no requests for revisions from participants.

\section{Summary}

This mixed method study explored student and parent perceptions around student mindset and reassessment, helping to identify how skills-based reporting at a rural Midwestern middle school has impacted student mindset. A student survey generated descriptive statistics and a semi-structured interview process were utilized with parents of students who attend the aforementioned middle school. Interview data was audio recorded and then transcribed. The interview transcriptions were then coded and organized into themes. Each transcription was performed on the same day the interview took place. Participants were asked to review the transcriptions to ensure authenticity. Chapter four will disseminate the study's findings. 


\section{CHAPTER IV: ANALYSIS OF DATA}

One purpose of this study was to uncover the reasons behind students' choice to reassess or not to reassess. The second purpose was to examine the role parent involvement plays in student choice to reassess or not. The results of this study consist of both quantitative and qualitative forms of data collected from both students and parents and are organized around the two research questions:

1. How has Skills Based Reporting at Farmersville Middle School impacted student mindset? Why do students choose or do not choose to reassess?

2. What role does parent involvement play in a students' choice to reassess?

A total of 358 students completed the survey. Analysis of demographic information gathered from the student survey shown in Table 1 indicates that the number of males completing the survey $(n=180)$ was nearly identical to the female participants $(n=178)$. Also, Danbury and Austin are the two most populated towns, each comprising nearly $20 \%$ of student survey participants. Macon (13.7\%), Hamlin (13.1\%) and Midland (10.6\%) were the other three towns with over $10 \%$ of participants. Just over one third of student respondents (34.4\%) reported they were currently taking an advanced placement class. Over seven out of ten students (71.4\%) reported that they participated on a school team.

Table 1

Student Survey Demographic Information-Questions 1-4

\begin{tabular}{lcc}
\hline \multicolumn{1}{c}{ Factor } & Number & Percentage \\
\hline Q1: What is you gender? & 180 & 50.3 \\
$\quad$ Male & 178 & 49.7 \\
$\quad$ Female & & \\
Q2: What is your town of residence? & 14 & 3.9 \\
$\quad$ Waynesville & & (table continues)
\end{tabular}




\begin{tabular}{lcc}
\hline \multicolumn{1}{c}{ Factor } & Number & Percentage \\
\hline Austin & 71 & 19.8 \\
Macon & 49 & 13.7 \\
Arlington & 18 & 5.0 \\
Midland & 38 & 10.6 \\
Hamlin & 47 & 13.1 \\
Salem & 26 & 7.3 \\
Danbury & 71 & 19.8 \\
Bloomfield & 17 & 4.8 \\
Other & 07 & 2.0 \\
Q3: Are you currently taking AP Classes? & & \\
Yes & 123 & 34.4 \\
No & 235 & 65.6 \\
Q4: Do you participate on a school team? & & \\
Yes & 255 & 71.4 \\
No & 102 & 28.6 \\
\end{tabular}

\section{Students Choice to Reassess or Not to Reassess}

In response to the question of how many times they reassessed within the semester, the most frequent response (188 students, or 52.5\%) was from one to three times. On the other hand, $26.5 \%$ of the students stated they reassessed between 4-6 times, and over twelve percent said they reassessed seven or more times. Only about 31 students $(8.7 \%)$ disclosed that they did not reassess at all. By far, the subject with the most reassessments was math, with nearly two out of three students $(66.2 \%)$ identifying math as the subject in which they reassessed the most. Following math in a distant second place was English (12\%), and then Science (11.5\%). The results on student's choice to reassess are shown in Table 2.

Table 2

Student Survey Results-Questions 5-6

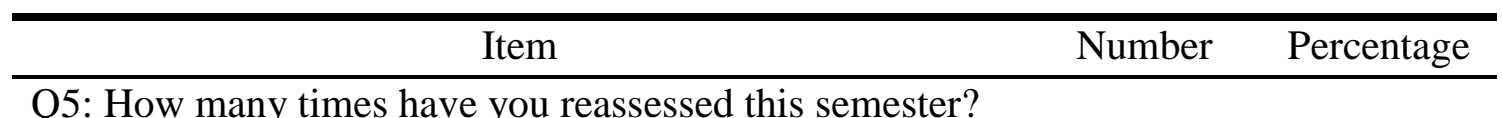




\begin{tabular}{|c|c|c|}
\hline Item & Number & Percentage \\
\hline 0 & 31 & 8.7 \\
\hline $1-3$ & 188 & 52.5 \\
\hline $4-6$ & 95 & 26.5 \\
\hline $7-9$ & 23 & 6.4 \\
\hline $10+$ & 21 & 5.9 \\
\hline \multicolumn{3}{|c|}{ Q6: In which subject do you reassess the most? } \\
\hline English & 43 & 12.0 \\
\hline Math & 237 & 66.2 \\
\hline Science & 41 & 11.5 \\
\hline Social Studies & 29 & 8.1 \\
\hline Encore & 8 & 2.2 \\
\hline
\end{tabular}

Results from further analysis of the data on student perceptions about the reassessment process, their viewpoints on perseverance, and if they would reassess based on the initial level of scoring are presented in Table 3. Students were asked to respond to five Likert scale items with options ranging from strongly agree (1) to strongly disagree (5). Most students (39\%) indicated they strongly disagreed or disagreed when asked if they were more likely to reassess if they liked the subject. Additionally, $28 \%$ indicated they were undecided when asked if they were more likely to reassess if they liked the subject $($ Mean=3.09, $\mathrm{SD}=1.167)$. On the other hand, about $43 \%$ reported they strongly agreed or agreed when asked if learning about perseverance encouraged them to reassess, even when they don't have to.

Table 3

Student Survey Results-Questions 7-10

\begin{tabular}{lccccccc}
\multicolumn{1}{c}{ Item } & SA & A & U & D & SD & M & Dev \\
\hline $\begin{array}{l}\text { I am more likely to } \\
\text { reassess if I like the } \\
\text { subject. }\end{array}$ & 33 & 85 & 100 & 96 & 44 & 3.09 & 1.16
\end{tabular}

(table continues) 


\begin{tabular}{|c|c|c|c|c|c|c|c|}
\hline Item & SA & A & $\mathrm{U}$ & $\mathrm{D}$ & SD & M & $\begin{array}{l}\text { Std. } \\
\text { Dev }\end{array}$ \\
\hline $\begin{array}{l}\text { Learning about } \\
\text { perseverance } \\
\text { encourages me to } \\
\text { reassess, even when I } \\
\text { don't have to. }\end{array}$ & 41 & 112 & 130 & 60 & 15 & 2.71 & 1.01 \\
\hline $\begin{array}{l}\text { When I earn a "2" I am } \\
\text { likely to reassess in } \\
\text { hopes of earning a } 3 \text {. }\end{array}$ & 98 & 121 & 88 & 39 & 12 & 2.29 & 1.08 \\
\hline $\begin{array}{l}\text { When I earn a "3" I am } \\
\text { likely to reassess in } \\
\text { hopes of earning a } 4 .\end{array}$ & 12 & 55 & 111 & 133 & 47 & 3.41 & 1.00 \\
\hline
\end{tabular}

Note. SA=Strongly Agree; $A=$ Agree; U=Undecided; $D=$ Disagree; $S D=$ Strongly Disagree; M=Mean; Std. Dev=Standard Deviation.

encourages them to reassess, even when they don't have to $($ Mean $=2.71$, Standard Deviation $=$ 1.012). Most students (61\%) agreed or strongly agreed they would reassess if earning a ' 2 ' on an assessment. On the other hand, when students score a ' 3 ' on an assessment, only $19 \%$ agreed or strongly agreed they would reassess.

Summary statistics for this series of questions include an overall mean of 2.766 .

Therefore, students generally agreed or strongly agreed to this set of questions. Responses range from an average minimum of 2.291 to an average maximum of 3.413 putting the range at 1.123 and a variance of .238.

On the next question on the survey, student respondents were asked to respond to a Likert-scale item with options ranging from extremely likely (1) to not at all likely (5). Responses are recorded in Table 4. In response to the question asking students how likely they were to try again after failing an academic goal, over $60 \%$ of respondents were quite likely or 
extremely likely to try again $(\mathrm{Mean}=2.32, \mathrm{SD}=.988)$. On the other hand, less than $4 \%$ of respondents said they were not at all likely to try again.

Table 4

Student Survey Results-Question 11

\begin{tabular}{lccccccc}
\hline \multicolumn{1}{c}{ Item } & 1 & 2 & 3 & 4 & 5 & M & SD \\
\hline $\begin{array}{l}\text { If you fail to reach an academic } \\
\text { goal, how likely are you to try } \\
\text { again? }\end{array}$ & 70 & 153 & 98 & 23 & 14 & 2.32 & .988 \\
\hline
\end{tabular}

Note. 1=Extremely Likely; 2=Quite Likely; 3=Somewhat Likely; 4=Slightly Likely; 5=Not at all Likely.

Table 5 reflects the responses from students when asked how well they can keep working if they struggle working on an assessment. Similar to the previous question a Likert scale provided five choices from which students could select options, ranging from "extremely well" (1) to "not at all well" (5). Most students (38\%) responded "quite well" (Mean=2.68, SD=.99). Table 5

Student Survey Results-Question 12

\begin{tabular}{lccccccc}
\hline \multicolumn{1}{c}{ Item } & 1 & 2 & 3 & 4 & 5 & M & SD \\
\hline $\begin{array}{l}\text { If you struggle while } \\
\text { working on an assessment, } \\
\text { how well can you keep } \\
\text { working? }\end{array}$ & 32 & 135 & 128 & 42 & 21 & 2.68 & .990 \\
\hline
\end{tabular}

The next series of questions asked students their perception on how much they could influence their outcomes. When students were asked how possible it was to change their assessment score, the most frequent response (41\% of responders) was quite possible to change $($ Mean $=2.30, \mathrm{SD}=.916)$. When asked how possible is was for them to change their level of effort, $44 \%$ of responders said it was quite possible for them to change. The mean for this 
question was even lower (2.09) and a standard deviation of .868. In response to the question asking how possible it was for students to change their ability to learn, $40 \%$ of students replied by answering quite possible to change $($ Mean=2.21, $\mathrm{SD}=.937)$.

Further analysis of data centered around student mindset. Specifically, students were asked to rate their perception of their ability to change their assessment score, their level of effort and their ability to learn. For the first question, "In school, how possible is it for you to change your assessment score?" the number of students responding "completely possible" was 70, with 145 students selecting "quite possible," bringing the total number of students who think it is quite possible or completely possible to change their assessment score to $215(61 \%)$. Of the remaining student responses, 115 selected "somewhat possible," 21 chose "a little possible" and 7 students responded, "not at all possible." the mean for question 15 ended up at 2.30 and the standard deviation .916. The second of three mindset-related questions read, "In school, how possible is it for you to change your level of effort?" Students were more optimistic in their responses to this question, with 251 students (over 70\%) believing it is quite possible or completely possible to change their level of effort. 87 students thought it was "somewhat possible" and 18 students selected "a little possible." Only two students thought it was not at all possible to change their level of effort. The mean for question 16 was 2.30 with the standard deviation of .916. Question 17 is the third and final question centered on student mindset. That question reads, "In school, how possible is it for you to change your ability to learn?" The responses to this question closely resembled the previous two. The most common response was "quite possible" with 144 students choosing that option. A total of $64 \%$ of students thought it was quite possible or completely possible to change their ability to learn, leaving 128 student responses spanning the categories of "somewhat possible" (103), "a little possible" (17) and "not 
at all possible" (8). Finally, the mean for question 17 was 2.21 and the standard deviation was .937.

Table 6

Student Survey Results-Questions 13-15

\begin{tabular}{llllllll}
\multicolumn{1}{c}{ Item } & CP & QP & SP & AP & NP & M & SD \\
\hline $\begin{array}{l}\text { In school, how } \\
\text { possible is it for } \\
\text { you to change your }\end{array}$ & 70 & 145 & 115 & 21 & 7 & 2.30 & .916 \\
$\begin{array}{l}\text { assessment score? } \\
\begin{array}{l}\text { In school, how } \\
\text { possible is it for } \\
\text { you to change your } \\
\text { level of effort? }\end{array}\end{array}$ & 95 & 156 & 87 & 18 & 2 & 2.09 & .868 \\
$\begin{array}{l}\text { In school, how } \\
\text { possible is it for } \\
\text { you to change your } \\
\text { ability to learn? }\end{array}$ & 86 & 144 & 103 & 17 & 8 & 2.21 & .937 \\
\hline
\end{tabular}

Note. $C P=$ Completely Possible; $Q P=Q u i t e$ Possible; SP=Somewhat Possible; $A P=A$ Little Possible; $5=$ Not at all Possible

Summary statistics for this series of three items resulted in an overall mean of 2.202. Responses ranged from an average minimum of 2.095 to an average maximum of 2.302 putting the range at .207 and a variance of .011 .

The final question (question 16) of the student survey took the form of a short response. Students were given a sentence starter, "I would reassess more often if..." then provided an opportunity to respond in written form. Similar to an interview, these responses were separated into main themes. The themes that surfaced from this student written response fall into these major themes: No need to reassess, the assessments are not easy enough, time, teacher feedback, 
making reassessments mandatory and liking the subject. Each of those themes are discussed next.

\section{No Need to Reassess}

The most common written response from students revolved around their perception that reassessment was simply not necessary because they were scoring fine to begin with. The following description provided by a respondent summarizes the litany of student feedback around this topic: "I don't really need to reassess much because I don't really get bad grades," wrote one student. Other examples of this line of thinking include,

- I got worse grades.

- I got bad grades on it first

- I got more ones and twos

- I would reassess more if I actually got bad grades

- I got worse grades. However, not meaning to brag, I get quite high grades and rarely ever have to reassess.

- I got more ones and twos, but I barely ever get any.

- I got a bad grade like 1 or 2 I would only reassess if was needed but if I don't need to I won't.

\section{Assessments are Not Easy Enough}

Another theme that emerged from the student response item related to the level of difficulty of the assessments. In their responses, students commented that "if the questions were easier," "if the assignment wasn't hard" and "there were an easier way to get the reassessment" then they would reassess more. Twenty-six responses along those lines contributed to this theme being categorized as such. Within these similar responses was the concept of confidence. Students wrote of their lack of confidence in improving their score by reassessing because the assessments did not come easily to them. The lack of confidence due to the rigor of the assessments appears to stymie students and prevent reassessment efforts. One student response 
included within it a solution to the issue. That response reads, "I would reassess more often if I had more self confidence in myself and had a Growth Mindset, giving me the inspiration to keep trying."

\section{Making Reassessments Mandatory}

Many students wrote that they would reassess more if they were provided more opportunities. Specifically, if the decision-making process was removed, they would reassess. Evidencing this are the following student responses to the prompt, "I would reassess more often if...”

- I was forced.

- If they told us we didn't have a choice.

- I was required.

- I knew I would get held back if I didn't.

- I am told to.

Providing students the autonomy to choose whether they reassess results in an unintended consequence of students passing up opportunities to master a skill. Interestingly, students freely explained that they would, indeed, put forth the effort to reassess if it was required of them.

\section{Time}

Students were cognizant of the commodity of time as it relates to reassessment. Many commented on various components of time, including that reassessment took more time, thus limiting their time to learn other concepts. Another aspect of time on which students commented on was when reassessments would take place. Several students voiced their wish for reassessments to come during class time, rather than coming in during lunch or a different time to reassess. Other respondents mentioned that having more time to study for the reassessments 
was necessary. Another popular response was that students would reassess more if there was an established routine of when reassessments would take place, with one student desiring a common time and place to be established for reassessments. This written response question highlighted that students very much value their time. Multiple respondents commented that they would reassess more often if they could simply fix the components of the skill they missed on the initial assessment rather than having to redo all components in their entirety. The following quotes evidence the various time-related themes from student responses.

I would reassess more often if...

- I had more time in class to do it.

- I had more time to learn the subject either during school or at home.

- The teachers would tell us when we are reassessing.

- They had a certain day and time to reassess.

- I could have a little more time to study for the reassessment.

- I didn't have so much weight on my shoulders from other things.

- I could only reassess on questions I miss rather than the whole thing.

- We took time in class to reassess, but we have to come in during lunch.

\section{Teachers Provided More Feedback}

The theme that elicited the most detailed explanation from students revolved around the feedback students felt like they needed from teachers to make reassessment a more viable option. Students recognized the teacher's role in learning. For example, students commented they would reassess more often if "Teachers would explain things a whole lot better," and "the teachers would be more flexible and would help me out." Other student responses took it a step further by stating, "We could go over the assignment so we understand it better," and "I understood what I 
did wrong to have to reassess." Another student opined, "Sometimes teachers do not always help you so I feel more hopeful if they did more often." This topic of feedback is central to this study's literature review and its importance was not overlooked by the student survey participants. Students appear to be thirsty for constructive feedback, as evidenced by one response requesting for "some type of paper to see what I need to fix." Another student desired for the concept to be "explained more in depth of what I have to do to change my grade when reassessing." Finally, another student wrote, "How am I supposed to know what I need to do to get better?"

\section{Liking the Subject}

Student interest in the subject area was a main reason that surfaced when students were given the prompt asking them what conditions needed to occur for them to more often reassess. Examples of student responses within this theme include:

- I am interested in the subject.

- I liked the subject.

- There were interesting subjects to learn about.

Perhaps the most descriptive of student responses that best summarizes this theme was, "If I don't like something, I will dread reassessing." That feeling was expressed in written form by five percent of the student body.

This concludes the analysis of student survey results. Next, findings from the parent interview will be disclosed.

\section{Parent Involvement in Student Reassessment}

Seventeen parents participated in the interview portion of the study. Two of the participants were male. All parent participants had at least one child attending FMS. At the time 
of the interviews fifteen parent participants had multiple children with at least one of their children attending an elementary or high school within the district. Sixteen parent participants had at least a four-year college degree. Each interview was conducted in a one-on-one format. Transcripts were transcribed verbatim. All transcriptions were read initially without coding to get a sense of the concepts as a whole. Then, a list of topics was created from within the transcripts, followed by the preliminary organizing of new codes and categories. Finally, categories were condensed and consolidated to topics that most closely related to each other. The following themes emerged from the data: Parents value opportunities to learn; second chances should be based on effort, not entitlement; Skills Based Reporting does not prepare students for life beyond high school; parents are confused about SBR; there is a fine line between perseverance and apathy; parent who are involved have high expectations for Growth Mindset and achievement. Next, those themes will be discussed in more detail.

\section{Parents Value Opportunities to Learn}

One of the main themes that surfaces throughout the interviews from parents was the importance of valuing opportunities to learn, including the necessity to learn from our mistakes. Each parent participant articulated their belief that people deserve second chances in life. "Everyone makes mistakes. That's how you learn," shared one participant. Another parent said, "I think that's very important to give opportunities for change. I think anyone can make an initial mistake and should be given an opportunity to learn from that instead of just one and done, you're marked for life." When narrowing the focus to academic second chances, the majority of parents held to their more general belief of second chances. Several participants commented that middle school is a perfect setting for second chances. "Especially in school because I see it as a learning experience. The goal is not to punish the child but to move them to a proficient level 
academically," shared one passionate parent. "There are times when kids don't understand what mistakes they made, on assignments, for example. There is a chance they can regroup and understand what needs to get done," opined another parent. "Middle school students especially make mistakes because their brain is still developing. If you don't understand it or you have problems, you should somehow be able to go back and relearn it and then give it another chance to see how well you understand it." Some participants included the behavior component in their reasoning for second chances. "Children are developing so any decision they make could be a rotten decision and not in alignment with their core values. I think that all plays into children and it comes into school, right? So from a second chance perspective as far as behavioral, yes, and I think including academically with reassessing because they may have had a bad day or not be a good test taker."

Within this first main theme of parents valuing opportunities to learn are key terms. Listed in the table ...... below are those terms and their frequency throughout the interview transcripts. Learning and second chances appeared most frequently (131 and 104 times, respectively), followed by risks (62 times), failure (49 times) and the ability for students to perform better (48 times).

Table 7

Parents Value Opportunities to Learn:

Key Terms

\begin{tabular}{lc}
\hline \multicolumn{1}{c}{ Term } & Frequency \\
\hline Mistakes & 15 \\
Challenge & 19 \\
Improve/Improvement & 29 \\
Better & 48
\end{tabular}

(table continues) 


\begin{tabular}{lc}
\hline \multicolumn{1}{c}{ Term } & Frequency \\
\hline Fail/Failure & 49 \\
Risks & 62 \\
Second Chances & 104 \\
Learn/Learning & 131 \\
\hline
\end{tabular}

Parent participants were unanimous in their opinions regarding second chances in general, which mirrored their belief that taking academic risks is a must. Each participant resonated with the idea that risks are necessary in life. "How else are you going to know that life isn't perfect?" commented one participant. "They have to jump off the diving board," said a father who used a swimming analogy. "They're going to have to learn to swim on their own. I can't hold them the whole time while they're swimming."

Many interviewees made the connection that taking risks in the school setting is a natural building block, particularly with Skills Based Reporting. Said one parent: "To go to the next level in anything you have to be willing to put yourself out there and try. I think you need to take risks to get to that 4 level, because that's above and beyond and most kids are not gonna achieve that unless they're taking some kind of risk." This participant recognized that even the reassessment process involves some level of risk. She reflected, “There's a risk they could reassess and it's not automatic, so there's a little risk there. They have to make that decision on whether they want to step out and do that." That same contributor followed up with this statement: "How do you know what your top level is without learning and taking those top-level risks?"

This common thread of students fearlessly embracing challenges and academic risks continued to weave itself through the interviews. "It's easy to play it safe, not matter what you're 
doing. But especially in the middle school years, they should start thinking outside the box and thinking differently and taking risks now. I think if we don't push those kids to learn differently and take those risks, most of them won't." Another parent shared the desire for school to be a setting that spurred risk taking to transform learning. In order to reach a level of learning that is transformative students will need to move into uncharted territory. "There's always risks with pushing yourself outside of your comfort zone. Outside the box can be an even better thing for you and that's a risk to go outside of what you know." Similarly, another contributor said, "If you don't take risks you're not going to succeed."

With risks come rewards, but also the chance of failure. Parents want their children to be successful but that does not equate to the absence of failure. "Failure is a good thing," one participant opined. "I think it would help [students] in life knowing that you have to continuously try to get better," said one parent. The parent interview participants shared their desire for students to aim for the stars and recognized that they probably won't land a direct hit on their first attempt. Summarizing that thought is the following statement from an interviewee: "I tell my kids a lot, whether that be athletically or academically, that they need to not worry about making mistakes and just go for it."

This first main theme characterizing parents' value on learning opportunities includes a subtheme on mindset. The aforementioned parent narratives essentially describe a desire for a Growth Mindset. Not leaving that to interpretation, several parents specifically described how mindset plays a role in learning opportunities. In fact, 94\% of parent interview participants were adamant in explaining that it was more important to them for their students to demonstrate a Growth Mindset rather than having the highest score. The following interview excerpt captures that thought: 
A Growth Mindset is so imperative to have a successful life and career. I just think you're setting yourself up for failure if you don't have a Growth Mindset. When I was helping coach, our big thing was, 'we don't lose, we learn.' You have to fail in order to succeed. But that Growth Mindset is what after failing keeps you trying and succeeding.

Again, parent participants did repeatedly emphasize their desire for their children to learn. "The ability to be taught things and the ability to learn I think would be more important. I don't get too hung up on the grade itself," explained one parent. Said a different parent, "I try not to put all the emphasis on the scoring mechanism. It's more about 'what did you learn and how did you go about learning it?' Another parent echoed the need for adaptability and the relevance it plays in the workplace: "You need that ability to learn and that will help you on jobs, no matter what it is. You're always going to need to pick up new skills. That ability to learn is more important than anything."

"I do think it's good for kids if [something] doesn't come naturally. It's good to let them demonstrate that Growth Mindset so they can see themselves that 'I can learn new things.' I may not enjoy it, it may not come easy to me, but I can achieve something that maybe isn't in my wheelhouse." One mother connected the value of a Growth Mindset to the social and interpersonal context by saying, "Just because you have an argument with someone doesn't mean you're going to hate them the rest of your life."

Such a mindset and focus on learning is not possible without the initial challenge. That concept was not lost on some parent participants as they brought to light that a high level of rigor that forces critical thinking may necessarily require more than one attempt to master. Should their students excel right off the bat without any academic struggle, those parents would question 
the level of difficulty. "I'm not saying they should never be proficient the first time, but I believe if we're challenging kids, they're not always going to be proficient," said this interviewee. "And there's nothing wrong with giving them a second chance if they want it and they want to put the effort forth. I don't expect my daughter to excel in every class she's in. In fact, I'd be concerned if she did because I don't think she'd be getting challenged." Rigorous and relevant instruction, according to the research participants, is an important piece of providing opportunities to learn. Another crucial ingredient for students to receive in order to take advantage of learning opportunities is feedback. One parent described the importance of feedback this way: "Giving [students] good feedback so they can know exactly what it is they need to improve on to get whatever their goal is--It's not so much a second chance as an 'I get to do it all over again', but 'how can I improve to meet my goal?' I think good, specific feedback to the rubric is very important."

Parent research participants made clear their belief that learning opportunities are crucial within life as well as the school setting. Parents shared their desire for students to be unafraid of making mistakes but rather embrace them as building blocks to learning. This theme plays a significant role in the study as the other main themes remain tethered to the concept of learning. Second Chances Should Be Based on Effort, Not Entitlement, Because That Reflects Life

\section{Beyond High School}

The second obvious theme that surfaced was parents' belief that hard work is the key that should unlock reassessment opportunities. The terms listed in the table below indicate the frequency of main ideas found relating to this theme. Parents mentioned the words work or working nearly 150 times, more than any other key term in the study. 
Table 8

Second Chances Should Be Based on

Effort, Not Entitlement: Key Terms

\begin{tabular}{lc}
\hline \multicolumn{1}{c}{ Term } & Frequency \\
\hline Do Over & 4 \\
Skin in the Game & 5 \\
Habit & 7 \\
Lazy & 7 \\
Effort & 8 \\
Accountability & 8 \\
Prepare/Preparation & 14 \\
Life & 33 \\
Job & 34 \\
Expected & 40 \\
Work/working & 146 \\
\hline
\end{tabular}

The following are several verbatim comments from parents describing this thought pattern. Each comment came from a different participant.

- Did the child put in the work to deserve a second chance?

- Did you actually put forth the effort the first time?

- What I'm challenged with is then are they working as hard as they can the first time?

- He's a smart kid, but there's a lot of smart people out there that don't go the extra mile.

- There's no doubt he's extremely smart and intelligent, but is he going to apply it?

- If you can't find time to do it the first time, when are you going to find the time to do it the second time?

- You're not always given second chances so you should try your best the first time. 
- If she received a 2, I'd have her reassess. But then again, if she didn't try hard enough the first time, that's what you're stuck with.

The aforementioned theme showcased how parents value learning opportunities. This theme highlights from the parent perspective what role students should have in the learning process. Being prepared is one element parents feel ties together with hard work. "In academic situations you're presented with the information, and you're asked to study. You're given the opportunity to prepare for that," explained a parent. Parents in this study made clear the learning journey is a two-way street and that students should have to meet some type of threshold before being allowed to reassess, essentially sinking some teeth into the policy. "I think there's something [a student] should have to follow to get a second chance," clarified a participant. "[Students] need some skin in the game," another parent declared. "If you don't take a chance studying, I don't think that kid deserves a 4." Another parent opined, "You can't blow it off completely. If you got a 1 then reassessed and got a 4, that tells me you did not prepare." Said another parent, “There needs to be something done on the student's part if they're going to reassess. You don't just get a 2 and reassess. It's not worth the teacher's time to grade it. It's not worth the student's time to take it." The idea of preparedness relates to formative assessments as well. While students at Farmersville only reassess on summative assessments, parents feel strongly deadlines should be met on other formative checks of learning including homework assignments. "I don't want to see that you owe a teacher the assignment. I know that assignment's not going to be graded and you can turn it in whenever you want, but there was still a due date on that assignment. You still need to hold yourself accountable to that," described one mother. The ability to responsibly meet deadlines is repeated by several. "If you're going to 
allow the reassessing it should only be allowed if you met the deadline the first time, [otherwise] it's not really teaching any accountability to a deadline."

Parents feel strongly that students should be preparing themselves for the learning opportunities the first time. A genuine concern and assumption that students are becoming entitled to second chances surfaced throughout the interviews. "There's a mindset with these kids at any age that they're gonna get a do over," said one father. "I've seen it in my own household and talking with other kids, described an interviewee. "I don't have to do it because I can fail this first time because I know I'm automatically gonna get a second chance. There's no repercussions for turning in late assignments. The mentality of the kids is that they don't have to do it until I need to do it." A different participant shared a similar concern by stating this from her child's point of view, "I didn't study last night so I'll take it and see what I get wrong, then study just that part I got wrong and then reassess on it." Another parent put it this way, "I feel that some of the practices are leading our kids to feel that second chances are the norm. He'll say to me, 'mom, I got a two but it's no big deal. I'll take it again tomorrow.' But second chances aren't the norm." Other parents described their understanding that during the learning process it may take a few times to figure it out but that schools should be careful not to set that expectation or students may feel "that that's how everything goes, but it doesn't."

While second chances may at times be necessary, parents also fear that allowing reassessments develops complacency and changes study habits. "What matters to me is that they're developing good habits," explained a mother. "I think when they take the first summative, they always have in their mind, 'I can always retake it.' That's the thing I think is the downside." 
"As long as they keep knowing they can reassess I feel like he just puts it off too much," declared one participant. "And I struggle with that." This father took it a step further with his exasperation of the lack of urgency from one student in particular by saying, "If you can turn it in six weeks late and still get a four on it...yeah, they learned the skill but it's teaching them bad habits."

It changes your study habits and I'm guilty of this, too. When I was in school you studied because you had one shot. Now, you might look over the material, 'hey, let's go give it a shot.' If I'm in middle school and get a three, then I'm [not reassessing]. Hey, I got a three and didn't have to study for it. Turn that around, if you get a two or a three on the initial then you go, 'okay I'll go study.' So, I think it changes your overall attitude, your overall study habits into this lack of detail and care.

Some parents recognized their role in the evolving study habits. "I'm somewhat guilty of that now because we are so busy. 'You've got a test tomorrow and you didn't tell me about it? Well, good luck. We'll see what we have to do after the fact."”

As research participants in this study, parents necessarily viewed things from an adult perspective. Each interviewee had a schooling experience and are now experiencing life in the workplace or with a spouse in the workplace. That explains why the common terms within this theme include the words "life" appearing 33 times and "job" with 34 appearances. A concern of the participants in this study is that Skills Based Reporting does not position students well to succeed following high school. One participant's comments summarized that fear: "My biggest concern is how are we preparing our elementary kids for middle school, our middle school kids for high school and our high school kids for job opportunities or college where they don't 
necessarily get reassessed when they don't study, or they aren't prepared for an assignment?" Echoed another parent on the lack of heard deadlines and responsibility, "It really sets them up for failure in the workplace. My boss would fire me.”

To review, participants felt strongly that second chances should be based on effort rather than entitlement. Having a prerequisite before reassessing would make parents feel better that students are truly earning their second chances rather than becoming lazy. Such accountability would affirm positive study habits that would continue to pay dividends in the future, particularly life beyond high school.

Parents Are Confused About Skills Based Reporting. Perhaps the theme with the most content provided by interview participants is that of parent confusion surrounding Skills Based Reporting. Parents sin (table continues) nderstanding various components of the system, ranging from the meaning of a 1-2-3 or 4 to the reporting and reassessment process. Common terms within the parent confusion theme are found in the table below. The table provides a glimpse into the thoughts of the participants. Over 200 times participants mentioned they did not know or understand something about Skills Based Reporting. In this section, the topic of parent confusion will be dissected.

Table 9

Parents Are Confused About Skills Based

Reporting: Key Terms

\begin{tabular}{|c|c|}
\hline Term & Frequency \\
\hline Judgment & 5 \\
\hline No idea & 6 \\
\hline Confused & 7 \\
\hline Gradebook & 8 \\
\hline
\end{tabular}




\begin{tabular}{lc}
\hline \multicolumn{1}{c}{ Term } & Frequency \\
\hline Communication & 9 \\
Information & 10 \\
Subjective & 10 \\
Consistency & 19 \\
Honor Roll & 20 \\
Don't know & 101 \\
Understand/ing & 116 \\
\hline
\end{tabular}

"I hate the grading system because I find it very difficult as a parent to understand." That statement from an interview participant is a concise, yet accurate summarization of this theme. Participants sprayed similar comments regarding the difficulty in transitioning from the traditional grading scale to SBR. "It used to be really clear cut," a responded said when referring to the traditional A-F grading scale. "I have no idea what a 1-2-3-or 4 stands for. I don't even think the kids understand it." Another participant had a nearly identical response as she said, "I don't like this grading system at all. I don't understand it. It seemed with letter grades to be black and white. I know whether you were doing well or not."

Overcoming more than a century of traditional grading practices has made the transition to SBR a challenge for parents. It could be considered akin to lifting a stain out of cloth that had been baked in for 100 years. These research participants are still tethered to percentages from averaging in the traditional model. One participant shared it this way: "Sometimes I think that the problem is that all of us grew up with and still have the mindset of the $100,90,80,70,60$. So it's a hard time correlating the 1-2-3-4. And I don't know if as a school we're all on the same page about this is a 1 , this is a 2 , this is a 3 and this is a $4 . "$ 
"I don't really know what a 3 or a 4 means," commented another parent. "Is a 3 [the equivalent of] $100 \%$ ? You just met the standards and $100 \%$ is a standard. Or is that a 4 and a 3 is what I would think of as a B?" Yet a different participant thought that, "If you got rid of the 1-23-4 and put it back to A-B-C-D I think parents would understand it more. What does a 2 mean? Is it a B-? I still have a hard time understanding it. We hear a 2 is a little below average but it's not the best thing, but it's not failing. There's no good translation between letter grades and this." This interview member commented that, "[If I were a teacher] I would take the 4-3-2-1 and then convert into points because it's just easier to understand. It's hard to get away from the letters. You're not supposed to think of a 4 as an A but how do you not think of a 4 as an A? What is a 4 if it's not an A? What is it $-120 \%$ ? Is $100 \%$ meeting or is that exceeding?" she quipped. The quagmire of the numbers, percentages and letters in the above paragraph shed light into what has caused the confusing implementation for the parents of Farmersville.

The perception of ambiguity within the SBR numerical scale fuels the confusion. Participants regularly mentioned the uncertainty in deciphering what a number really reflects. At times a confused child intensifies the anti-SBR elixir for parents. One frustrated participant described her daughter as a perfectionist. "I question how much SBR is making it worse," she said. “'What do I need to do to get a 4?' There's never a clear answer, which makes [the child] think this is never quite enough. We want kids to work hard and strive for more but at some point in your life enough is enough."

The concept of biased grading practices surfaced throughout the interview in a myriad of terms with "subjective" appearing most frequently (10 times). "Unfortunately $\{\mathrm{SBR}]$ is extremely subjective," cried one interview partaker. Said another, "One of the things I struggle with is that [SBR] at time seem to require more judgment and it's more subjective," said one 
interviewee. "That's something both parents I've spoken to and student struggle with." That same participant did recognize that subjectivity may exist regardless of the grading scale. She goes on to say, “I don't know if that's unique to skills based but from the outside it appears that there perhaps can be more judgment as to whether a student has attained a skill, especially looking at the rubrics." A different participant also recognized that teacher discretion will always result in some interpretation with student grades. "Let's be honest. There's always going to be a level of subjectivity," the participant noted.

Each time participants referenced teacher subjectivity with SBR and the overall score designated for the student. "To me that 3's and 4's category is a very gray category and when I talk to teachers about it, they think so, too," explained one female participant. [Teachers] can't tell me this is why she's getting a 3 and not a 4 , so that seems like a very gray area." One parent participant went as far as telling her hard-working daughter who was trying her hardest to reach a 4 to disregard what feedback the teacher provided regarding the grade level designations. "I'm trying to teach her not to care what the teacher is saying [about 3's and 4's] because it's so subjective," that parent stated. "She's gotten to the point where she has started to not care because she knows whether or not she's done her best work."

At the middle school level in this school district, students encounter more teachers including one for each core class as well as encore, or elective classes. The shift from the elementary school model of having one predominant teacher to 8-9 in middle school is a large shift in and of itself. While each teacher is following the same SBR criteria and philosophy, they are teaching different contents and assigning different types of activities and performance assessments. This variety of teacher personalities, content areas and scores entered in gradebooks provide to parents a plethora of opportunities to become overwhelmed or confused. Many 
participants in this study commented that the difference between their students' scores are predominantly based on the teacher rather than their students' skill level. 'I don't think there's consistency with the teachers," stated one participant. "I think some teachers grade differently," shared another parent. "I know this happens in PE. These girls were in two different classes and they did the same thing all day and one of them got a two and the other one got a three. So, sometimes I wonder if sometimes it's partial on the teacher.”

The perception of inconsistent application of scores between teachers fuels the subjectivity skeptics. A mother made the following comment about the lack of consistency with SBR across classes: "I don't think they fully understand it yet. [My daughter] came home and said a 4 is an A, a 3 is a B, and I said, 'well, I don't think that's how this works.' Then she'll say in a different class, this is what [the score] means. So she doesn't have an understanding. I think a 4 should be a 4 across the board," she concluded. Sharing a similar thought, this participant stated, “[My children] perceive an inconsistency between teachers is that some teachers don't know how to do it. And that may not be the case I just think the teachers probably apply it a little bit differently, but it leaves the students confused from class to class how it's going to work."

Any lack of understanding about SBR from the students only magnifies parents' trouble in finding clarity with the system of reporting. "I think the practice becomes a little more difficult and I think inconsistency is probably the reason for that. I find that students are confused often about how it is going to be applied and therefore parents tend to be confused as well,” cited one parent. Another parent stated, “[My child] is not lazy, but she doesn’t care [about reaching a level four] because we've had multiple experiences where the teacher could not tell her how she should do better to get that score." 
Concern of teachers inconsistently implementing the practice was a routine comment from research participants. However, the inconsistency feelings did not stop at the classroom level. Farmersville Middle School operates on a 4-3-2-1 numerical scale but when students are promoted to Farmersville High School, a letter grade is provided at the end of the semester to designate an overall grade. High school students still receive feedback via 4-3-2-1 throughout the semester but to better assist with college application processes a letter grade is accredited to students based on students' latest demonstration of skill. The same mantra can be heard at both the middle and high school level: 'A four is not an A; a three is not a B;' etcetera, etcetera, although parents still report hearing school staff provide such comparisons.

Parents who have children at both academic levels find the differing approaches to implementation a heavy burden to bear. One parent said, "I just don't think there's a consistent way that it's being implemented across the districts that are using it." A father with children in both schools elaborated a little more by saying, "Middle school seems totally different than high school. [High School] is just not comparative to what we're doing in the middle school. It feels like we're on two different paths."

"Consistency between middle school and high school--I just don't think it's there," decried this participant. "I don't feel there's consistency with explanation of what those numbers mean. Again, [in middle school] a 3 is good. In high school, the 3 translates to a B and the 4 translates to an A. It would be nice to have consistencies throughout." An area where the school could work to clarify is what constitutes an A, stated one participant. "You can say in middle school, 'don't think of it that way,' but then you get right back to high school and you have to think about it that way," she stated. 
Parents with students in both middle and high school inevitably grow to like one approach more than the other. The following interview excerpt is from a mother who prefers the middle school adopt the high school's protocol. "Is there any way the middle school can do it like the high school does and put the letter grade on stuff or is it always gonna be a constant 1-23-4?" she asked. "Because I think as a parent for me to look at the one in high school you can see that letter grade, but you can also see where she's gotten 1-2-3 or 4 in other assignments." Seeing things from the other perspective, this interviewee could not come to grips with why the letter grades crept back up in high school. "Attaching a grade in high school for skills based--it's beyond my understanding," she said. The back and forth continues like a tennis match volley. This parent shared the following when referring to the addition of the letter grade at the high school level:

"I mean, if we're gonna get a grade at the end, give us a grade throughout. I'd rather see an A-B-C in there rather than a 1-2-3-4. Supposedly those numbers don't coordinate to a letter grade, but let's be honest with ourselves--they do! That's why it's hard for me with [my middle school daughter] to accept a three because in high school, ultimately that's a B. So, I don't understand it. Why are we giving them numbers up there when we have to give them letter grades?"

Further evidencing the concern of parents is situating their student for success with college placements. Parents at the middle school level are torn between forcing their child to reassess with a three even though they have already met the standard. "I don't know if a three is acceptable when you're looking at college applications," explained one parent. "I don't want to push her too hard. I just don't know what I should be teaching her what she should be striving for in high school." One father described that regardless of the middle school's lack of emphasis on 
letter grades, it's the hard numbers that really matter. "I've gone through the college admissions process the last two years with my older kids and it's all about the numbers," he said. "What's your GPA? What AP classes are you taking? What were the scores in your AP classes? What was your SAT score? All those numbers get you financial aid. This may be wrong, but from a college perspective, the scores are what matters."

Adding to the level of parent confusion is navigating the report card on Skyward, the district's Student Information System (SIS). Parents made clear their confusion with interpreting an individual score on a formative or summative assignment. The student gradebook includes multiple scores within each skill and each content area, leaving parents a very thorough, albeit confusing rendering of their child's academic and nonacademic performance in school. "I'm not the best at checking Skyward," said one parent. "I find it hard to use." This thought reverberated throughout nearly each interview participant. "I'll be honest, Skyward is a little challenging to figure out. Where do I go? Is everything up to date?" exclaimed one exasperated parent. Others commented that once the initial challenge of locating the gradebook has been accomplished, the real challenge begins. "When I look at the gradebook, it's not clear what is summative and what is formative because there are no point values. My husband is a well-educated man, and he gets into Skyward to look at the gradebook and he's like, 'what the heck does this even mean?"” shared one parent participant. Another participant shared a similar experience with her spouse when she presented him the report card, "It's like a foreign language to him. He has no idea what this means. Some clarification would be helpful, I think." Other parents skip the gradebook altogether. "I really don't put a whole lot of value in the report card," shared one parent. "Simply because, when I call the next day and ask how he needs to improve the teacher will tell me 'well, he's already at a four.'" With formative checks to provide teachers with consistent checks in 
student understanding as well as the ability to reassess, students' scores are more malleable and fluid, making parent accountability more difficult.

Parent confusion with SBR continues with a lack of understanding regarding the reassessment process. "When I do look at Skyward to see what's going on, it's not always clear and there is usually some explanation about why the grade is low because they haven't reassessed yet," described one parent. Some participants link the lack of clarity on reassessment procedures with the low reassessment numbers at the middle school. "I think the challenge is understanding the [reassessment] process," exclaimed one parent. "I don't always know when they're doing an activity that can be reassessed." Other participants shared similar stories about not always knowing when reassessment opportunities are available. "I will say [parents] have been a little foggy with the whole grading system because sometimes they're allowed to reassess and sometimes they're not," shared another parent. Some participants cited a lack of communication from the school to the confusion. Another participant stated that his children as well as the school do a good job of trying to explain Skills Based Reporting, but that ongoing development is needed. "I would like to see more communication between the teachers and the parents. We've had our workshops and had it explained to us but we need to hear it more; we need reminded. There needs to be more transparency of how teachers are coming up with the scores on reassessments." A parent new to the district stated that "I think there needs to be more information for parents as far as how things are assessed and what teachers are looking for." Similarly, other participants were interested in the assessment process. "That's the part that would be nice to know as a parent," cited one participant. "How are those individual assessments happening? Is it based on the assignments they're turning in or their participation? I'm assuming there's individual judgment in there." Parents expressed that when they do look at the particular 
skills students are working on, they try to examine the learning process and where the gap may have occurred. "You don't get every paper back home and sometimes it's difficult to see what exactly is getting assessed," explained one mother. The major shift in grading and reporting has created a robust craving for communication on behalf of the parents. "If teachers feel they are communicating to the extent they think they need, I don't think they are," stated one mother. "It appears to me that teachers claim that everything is fine, but it's not fine because he ended up with several two's."

For parents who recognize that SBR emphasizes growth over time, they may be less urgent to force a student to reassess, thinking that the opportunities will naturally occur throughout the semester. One parent stated it this way, "Students get a two but think, well this is just one summative — next time I'll get a three. It's the end score they're supposedly going after. Maybe parents are looking at it like that, too. There's probably no need to reassess because we're trying to grow throughout the year. Whereas you put a letter grade to that and parents understand.” Parents fall back to the inconsistency among reassessment practices. Some claim teachers tell students they cannot reassess to get a four. Others have heard that if a two is earned on an initial assessment a student loses the possibility to ever earn a four in that skill. That misinformation may be curtailing some of the reasons for reassessments according to the interview participants. "So the teacher is saying he can reassess and the kid is saying, it's fine I got a two, explained one father. Some parents, he explained, have no desire to live in the weeds of specific skills but want to see the broad picture. "I'm still in the mindset of, 'overall what do you have?' and that's not valid anymore. I just want to know how my kid is doing. Does he study well? Is he turning in assignments?” One way Skills Based Reporting allows students to get such 
a glimpse is through the reporting of non-academic information. But, as you will see, even reporting on non-academic performance is not without critique.

A final component triggering parent confusion with SBR is the process of reporting nonacademic skills as well as the student recognition process. Parents still very much value the traditional avenue of recognizing students via the honor roll, as evidenced by how frequently it was discussed in the interviews. "We don't want twos," explained one participant. "He likes standing in front up there at the awards assembly and saying, 'look, I'm on the high honor roll.' That feedback is good for him.” A different parent described her son as being goal driven but that had not always been visible until he did not make the honor roll. "He always got high honors. He never said anything about it, so I didn't know it was a big deal—until he didn't [make high honors]. Then I knew it was a big deal.” Dovetailing Skills Based Reporting and honoring students for their academic prowess has not been without challenges. "If you looked at his report card he had all fours and threes but only a couple twos out of all those lines, but he never made honor roll," explained one parent. "So for him and me that's very discouraging because there's just one area it's not good enough to get honor roll. It's just a very small thing that he couldn't' get honor roll for it." Another participant was curious about the thought process behind honor roll and high honor roll for middle school. "You could have all three and still be high honors but another student could have a lot of fours but one two and wouldn't be in high honors based on a skill that could be very subjective," observed the participant. Finally, one mother explained that while she values a Growth Mindset for her children, earning fours are still important. "I don’t think the rewards are as strong in middle school as they are in high school because you don't have the grade or GPA attached to it." While SBR is designed to more accurately recognize students for their academic ability, the scoring mechanism continues to be a source of intrigue, 
one way or another. The non-academic scoring component is the driving force for more accurately reflecting students' academic performance. At Farmersville, students are provided feedback from teachers in each class around five learner skills district leadership determined to be important throughout life. The scoring on these skills of respect, responsibility, perseverance, self-advocacy and collaboration is reported as a 'mostly' 'sometimes' or 'rarely.' The separate scoring apparatus for learner characteristics paves the way for a more filtered and accurate academic report but is yet another adjustment area for parents. "I don't' like or appreciate teachers grading my student on personality. In my heart it bothers me that's even part of a grading system because how do you know what's in a child's heart? I feel like that's my job as a parent, so I think the teachers should focus on the academics," she stated. Other parents recalled the familiar feeling of inconsistency within this arena as well. However, the general consensus among parents was that reporting on these learner characteristics was important because parents value them just as much as academic progress. "I love those skills and I even have more I'd like to add," shared one parent. Said another parent, "There could be straight-A students with horrible attitudes who are disrespectful and don't persevere because they're used to everything coming easy." She continued, "I think that's huge to look at a kid to see how they respond when challenged academically and if they persevere."

The aforementioned examples from participants provide a hint of the frustration caused by the shift to a competency-based learning approach. "It is messy," said one mother bluntly. "I have never been more confused with where my kids are than right now. So my attitude is, I see those 3's and 4's and we're gonna roll with that, but we need to get serious when we get to high school.” From not understanding the overall concept of Skills Based Reporting, to being 
skeptical to the subjectivity and inconsistency among teachers, parent confusion with SBR was a major theme in this study.

\section{Parents Who Are Involved Have High Expectations for a Growth Mindset and}

Achievement. The next theme that will be examined deals with parent involvement in the reassessment process. In short, parents portrayed high expectations for their children to succeed but also recognized the importance of having a Growth Mindset along the way. As with before mentioned themes, a table accompanies this section that reflects the frequency of key terms aligned with this theme of parental involvement.

\section{Table 10}

Parents Who Are Involved Have High

Expectations for a Growth Mindset and

Achievement: Key Terms

\begin{tabular}{ll}
\hline Term & Frequency \\
\hline Peers & 6 \\
Motivated & 10 \\
At home & 18 \\
Good enough & 12 \\
Perseverance & 24 \\
Mindset & 43 \\
Grades & 70 \\
Parents & 149 \\
\hline
\end{tabular}

When asked whether their child would reassess if given the opportunity, nearly every participant reported that their child would, indeed, reassess. "If they have the opportunity to improve, they're going to take that opportunity," reported one parent. "Neither one of [my children] wants to fail so they're going to try and persevere.” Another participant thought 
reassessment chances offer parents the ability to model the importance of persevering through struggles. "Our youngest does not want to reassess but we're teaching her about perseverance and telling her she needs to reassess in different instances," described this parent. Parents in the study were quick to point out that their children did not always want to reassess, but that's where parents who are more involved with their child's academic lives make a difference. Participants shared their thoughts on why other students do not take advantage of reassessment and why if it weren't for them, their own children would settle with a subpar score. Below are specific examples, each one coming from a different participant:

- He's happy with a three and doesn't want to strive to get a four.

- They felt they did as good as they could the first time.

- He wants to just be done with it and have it over with and doesn't want to reassess.

- They don't want to take the time to redo it.

- I think it's just contentment. Great, I got a three! I'm good with that.

- They didn't study the first time so why would they want to do it again?

- Well, I got a two, I guess that's what I am.

- What's the benefit of getting a three? I'm not going to get a detention. I'm not failing. I can still play sports. I can get by.

- They already did it. They're done. That's the mindset. I did that assessment and I'm moving on to whatever is next.

- It's good enough.

These opinions and reports from parents demonstrate the difference between perseverance and apathy lies with the student but can be influenced by the parent. Said one parent regarding his child's attitude on reassessment, "He will not take that opportunity to get 
from a two to a three unless I know about it and I say you're going to try for that three." A different participant noted that even though her children struggled through some units the parents were there each step of the way. "We're the cheerleaders," the parent said. "Sometimes it's difficult for someone their age to get but we tell them you have to keep working through it and one of these days the light bulb will go on." Parents in the study reported that routinely having conversations with their children pertaining to school and reassessments naturally allows the parent to hold them accountable. "I hound them," described one parent. "I require them to reassess even though it's not required on a school level. I tell them you didn't perform to your capabilities so you need to do it again." A different participant shared her personal policy with reassessments, saying, "If they get a two, it's my expectation they're reassessing whether they want to or not. The three to a four is where I give them a little more leeway." Said a different parent, "I talk to her every day about school so any time there's a test or reassessment we talk about it." Another participant described the evening routine of her family, saying, "We eat dinner together most evenings. We sit down and ask 'how is school-how's it going?' Is there a test coming up?' It comes up in conversation," she said. To drive home her honest thoughts on parent involvement, this passionate participant stated the following:

If you're going to be given the opportunity to reassess something and learn the concept you should take full advantage of it. I think if you don't have parents at home on top of them, they're going to be fine with what they get. And if you don't have a parent that's holding them accountable at home and twos are fine at home, why would they reassess? I wouldn't.

Finally, one respondent summarized by saying, "If parents aren't communicating with their kids about how important school is and holding them accountable, I think [reassessment] goes by the 
wayside." Some parents took their views of reassessment so far as to say that students should not even have a voice in determining whether they reassessed. "I don't think [reassessment] should be mandatory but I do think it should be left up to the parent," explained one parent. Echoing that, a different parent said, "I think it should be more up to the parents than the kids to make the [reassessment] decision.” Repeatedly, parent participants in this study cited continuous conversations they have with their students on the topic of tests and reassessment chances.

Other participants noted that not all students may have such a supportive environment. "There are types of students who need that second chance to get their grade up but may not have all the support they need from home," explained one father. That support may appear or be lacking in various forms. Said a different participant, "I think it's what [the student] gets at home, you know? What are you going home to? If you're starving, who cares about a two, I want something to eat."

Although parents recognize their ability to hold their children accountable, they also see the benefit in empowering their students to take ownership of their own learning. "Sometimes [the children] need to take the reins," said one participant frankly. "I would like him to reassess with a three but he's also 14 years old and we've got to start understanding there's consequences for your actions and at some point he has to understand that choosing not to reassess will have potential outcomes later on," he added.

"This is a delicate balance," described one mother who recalls a lot of pressure being put on her as a straight-A student in school. "I certainly don't want to instill that pressure on my children. You hope they have the self-drive and discipline that they just want to do it." Some students have developed that habit. "A lot of times he'll bring [the assessment] to me and say 'I got a two on that' or 'I got a three on this', so I use those opportunities to check on whether he's 
reassessing," described one parent. "He initiates most of that." Another parent describes the approach she uses to empower her son to take ownership of his education. "I tell him all the time, 'do you think I can get on the honor roll? No, I can't do that. I can encourage you, I can go talk to your teachers and send emails but [you're] the person who's getting these grades.'” Parent participants explained they have tried to develop assertiveness and self-advocacy within their child to clear up confusion about scores by approaching the teacher or emailing them. "I've tried to teach [my child] that because I don't always want to be that parent who is intervening," said one parent. Owning their learning is something that parents feel will benefit students well beyond middle school. "When you send them off to college, they're on their own. If you have a problem with the professor or the grade you got, don't call me," said a mother explaining her philosophy behind empowering her students to take charge of their schooling. "To me it's my job to help them do as well as they can and it's important for them to look at their own grades."

Finding the balance between student ownership and parent oversight is indeed a delicate process. For example, when parents were asked if they would like to be notified by the school when their child had an opportunity to reassess but chose not to, participants overwhelmingly responded 'yes.' Despite the parents' emphasis on students taking ownership of their learning, parents made it clear they still wanted to be informed in such instances, even if it meant several times per semester. "I think that would be nice to know because as we all know we get really busy with our kids at a certain age," rationalized one parent. "It would be nice to know if they had that opportunity and passed on it." After sharing a similar statement, a different parent recognized that as a growth area for himself. He noted that if he was better engaged at checking his child's scores and knowing which scores could be reassessed, he could provide better parental support. Another participant noted that while she did not believe parents should be 
completely responsible for knowing about reassessment opportunities, parents should be made aware if there's a pattern of behavior regarding reassessments. Two parents vehemently disagreed with the notion that schools should notify them each time a student opted out of a reassessment. "I have Skyward. That's my responsibility. [My daughter] should be checking it; that's her responsibility," believed one parent. Said another parent, "It's not [the teacher's] responsibility to put in another stopgap, it's my responsibility as a parent to understand what's going on with his grades." She continued, "If I'm not comfortable with what he's telling me I know how to use email and I know how to use a phone. But to me, that's mom and dad's responsibility." Finally, a different parent participant suggested a policy that would straddle the line between complete parent control to complete autonomy of the student. If the child took responsibility and filled something out that indicated he chose not to reassess it would be best because it's "putting it back on the kid to let the parent know," she said.

Parents undoubtedly believe in the importance of being involved in their child's lives, including their educational experience. The interviews within this study revealed a desire for parents to take a different direction in their involvement. Rather than simply encourage students to work hard and perform well, parents are discussing mindsets with their children. The word mindset was mentioned 43 times over the course of the interviews - a substantial number reflecting its important role within this context. The parents did reinforce their high expectations for students to perform but built those beliefs on the foundation of a mindset that will catapult them into productive careers and foster lifelong learning. "My expectations are high," explained one parent. "We aren't okay with just average," echoed another. "Grades matter. It's just a fact. It's the way our structure works. I don't mind if they don't have perfect grades as long as they're working hard and learning something.” Another parent wished the school would force all 
students to reassess on everything until they earned a four. "Unless you got a four there's always room for improvement," stated this zealous participant. "I'm encouraging my kids at home that even if you got a three, talk to the teacher about what you could do to close the learning gap." It was clear the parents in this study set the bar high for their children, but the theme of overcoming obstacles continued to appear in parents' statements. "I want you to have the chance to really learn or relearn the concept, but I want to hold you accountable to actually sitting down and spending the one hour, two hours, five hours to study that and be ready for your test when the test is given," replied one parent. Said a different father, "We always strive for the best. We're not always going to be the best but I feel it's very important that if you're giving them the opportunity to retest they should take full advantage of it because it's all about growth." Yet another parent confessed that she did want her daughter to work towards high achievement and to be the best at whatever she does, "but it's how hard she works and her attitude along the way [that matters most]. It's not the final achievement," concluded the parent. A participant with outspokenly high expectations for her children was aware that some people may think she expects a four all the time for her kids, but not to confuse grades with what really matters to her. "I'm good with a lesser score if I know what my children are learning will carry forward to the next class and beyond." She concluded her statement by saying, "If they don't truly learn and understand the concepts in the beginning, how can you stick them into an AP class?"

One parent believed that SBR was inadequate because there was no zero included in the scale. "I think kids have to be allowed to fail," she said. "When you expect your kids to perform I think it's a travesty for [students] not to know where they stand in their class of peers," she continued, citing the district's abolition of class rank and valedictorian. I think kids learn a whole lot when they're allowed to fail." Of course, this parent also believed strongly that identifying 
the failures early in the semester and taking advantage of reassessments was necessary. That parent's emphasis on the growth rather than the score was similar to another respondent who stated, "Sometimes you need to work on the kids' mindset. We're trying to teach kids to have ownership. If they're completely satisfied with a two or a three, they have to own not only that score but their mindset, too."

Despite recognizing Growth Mindset as a positive attribute, parents still notice their children not wanting to attempt the higher score for fear of failure. "Some of those four questions are kind of a scary thing for those kids because it's above what they think they can do," one parent explained, "so maybe there is anxiety that she feels like she's going to fail if she tries a for a four, so she doesn't because a three is good enough.” The more common response from parents was that peer perception regarding reassessment trumps a student's Growth Mindset.

"Everything is peer driven in middle school," observed one parent participant. "There needs to be a privacy component. If there was a more private, discreet way of handling things, maybe there would be more reassessment." The notion that peers are aware of the reassessment patterns of others was not lost on other participants. "I think academically he doesn't want to look stupid in front of his peers," cited another interviewee. "I think a lot of [students] are like him and they think [reassessing] is showing weakness. I think they don't want to be weak in front of their peers." Finding a way to change the persona on reassessment may be the key to unlocking more reassessment attempts. Another parent likened reassessments to practices that athletic teams hold each day. "It's just like practice and showing us you're willing to try and better yourself," she noted. "It's like missing a free throw. You're going to practice and try again." That same participant observed that some students already have the internal drive to continue striving for proficiency, while others need some encouragement to embrace the Growth Mindset that Skills 
Based Reporting promotes. “We have those kids that aren't quite there. They haven't bought into academics as being so important that I need to keep trying and reassessing because I'll get better at that skill." Parents noticed that even if students don't take advantage of the reassessment opportunities it still provides an avenue to discuss their mindset regarding academics and even other topics.

Respondents also noted that talking about Growth Mindset increased with the dawning of Skills Based Reporting. “I really hadn't heard of [Growth Mindset] before skills-based came along," mentioned one parent. "I think that's important and glad we're discussing that." Other interview participants shared their belief that Skills Based Reporting has fostered a Growth Mindset in their children. "I think SBR encourages that," said a mother. Another respondent said, "My oldest child tends to get high marks without having to try too hard so for her this emphasis on skills forces her to embrace a Growth Mindset and the ability to learn in different situations." Finally, another parent explained that the SBR has prompted a deeper glimpse into how the parents and children view their education but also their outlook on learning. "I don't know how many times [my daughter] walks away from her Chromebook and says 'I'm done,' but then comes back and gets it. When [my son] gets the assignment and it's one he struggles with, he'll walk away and go play Fortnight or something." That respondent noted those study habits are easy to connect with reassessment practices and student mindset overall.

The fact that Skills Based Reporting has attributed towards students and parents either adopting or at least recognizing the absence of a Growth Mindset is not the only positive the participants discussed. Parents were quick to share irritations with SBR but many recognized the positive qualities it brings to the district. "I like it. I do like the concept," confessed one father who embraced the idea of adopting a strategy in an effort to improve. "We need to evolve as a 
school district and get better." A different respondent, this one a mother of two middle school students, said, "I think I like this Skills Based Reporting. It gives kids the opportunity that need more help, even if it takes them a little longer. I definitely think it's great for kids.”

"I do like the theory behind it," shared another parent. "I think it makes sense. Any time there's change there's going to be resistance." Echoed another respondent: "There always has to be controversy. If there is controversy, something is clicking. More education and training that can be provided always seems to help that out." A different participant could not hide her enthusiasm for the direction Farmersville is heading as a district. "I'm so happy [Farmersville] is going the way it is with Skills Based Reporting. I know it is helping equip [students] with the mindset to prepare them for the careers they want and just to be successful in life." Several respondents noted they were initially dissenters to this assessment and reporting model but once they sought to understand it they began to believe in the concept.

\section{Summary}

Chapter four presented and discussed the findings of this study based on data from the student survey and parent interviews. Students were more likely to reassess in math than in any other subject. Students also reported they were much more likely to reassess when they initially scored below grade level expectations as opposed to reassessing to achieve a score beyond grade level expectations. Initial themes were generated and consolidated during the data coding and analysis. The identified themes included parents' value of learning opportunities, their belief that reassessment should be based on effort rather than entitlement, the aspects of Skills Based Reporting that cause confusion for parents and finally, that parents who are involved have high expectations for their children to demonstrate a Growth Mindset as well as achieve at a high level. A predominant component of parent feedback was the confusion resulting from the scoring 
mechanism of SBR. Participants lamented the differing scoring structures between the middle school and high school, the inconsistent and subjective assessment between teachers, and difficulty interpreting which assessments were able to be reassessed. The insights gleaned from the data provide the light that will illuminate improvement strategies. Chapter five will involve the conclusion of the study, including recommended action steps. 


\section{CHAPTER V: DISCUSSION, RECOMMENDATIONS, \& CONCLUSIONS}

Two main purposes guided this study. One purpose was to uncover the reasons behind students' choice to reassess or not to reassess with the other being to examine the role parent involvement plays in student choice to reassess or not. Within this chapter, the findings of the study are summarized and discussed. Implications for practice are also discussed in this chapter as well as limitations of the study, and recommendations for future study in the arena of Skills Based Reporting and competency-based learning are presented. Finally, conclusions are drawn from the study findings.

\section{Summary and Discussion}

\section{Student Choice to Reassess or Not}

Research question one reads, "How has Skills Based Reporting at FMS impacted student mindset? Why do students choose or do not choose to reassess?" Analyzing student survey responses has produced several conclusions. For example, 99\% of FMS students believe it is possible to change their level of effort, and $98 \%$ of students reported their belief that it is possible to change their assessment score. Similarly, $98 \%$ of students believe their ability to learn is changeable rather than fixed. These three metrics are key in determining the mindset of the student body. The nearly unanimous results signal a strong awareness from students at FMS of a Growth Mindset. Research (Brock \& Hundley, 2016; Dweck 2006) indicates a Growth Mindset produces more favorable academic results. Based on this study, students at FMS are saying they have a Growth Mindset. Therefore, it can be concluded that students at FMS who choose not to reassess do so not as a result of having a fixed mindset.

Students at FMS have been explicitly taught the core skills of collaboration, responsibility, respect, self-advocacy, and perseverance. When asked if learning about 
perseverance encouraged them to reassess, $42 \%$ of students stated they did, indeed, believe learning about that skill encouraged them to reassess. That figure is telling as it does not speak to a student's level of perseverance but rather their belief that learning about perseverance influences one's ability to demonstrate the skill. However, nearly $2 / 3$ of students said that they are quite likely or extremely likely to try again after failing to reach an academic goal. Finally, two questions were posed to students asking them the likeliness of reassessing with an original score of "2," which is below proficiency, and the likeliness of reassessing with an original score of “3,” which reflects skill attainment. Despite demonstrating skill proficiency, students still have the option of reassessing to demonstrate advanced skill mastery, recognized as a "4" in the Skills Based Reporting system. A strong majority of students stated they agreed or strongly agreed that they would reassess with a "2." That figure dropped dramatically if students scored a "3" on the assessment, reflecting a contentedness on behalf of students with achieving skill proficiency. These results point to a student body that overwhelmingly reflects a Growth Mindset, which is caused at least in part from students learning about perseverance. The positive impact of SBR including the instruction of core character skills such as perseverance is directly supported by the prevalence of students reassessing when initially scoring below grade level proficiency.

In the written response portion of the survey, one theme included that students would reassess more often if they liked the subject. That specific question posed earlier in the survey solicited a response of only $39 \%$ of students agreeing or strongly agreeing they were more likely to reassess if they liked the subject. The student response overwhelmingly stated that math was the subject in which students reassessed the most.

The second portion of the first research question simply sought to explore why students chose to reassess or chose not to reassess. A simplistic avenue was used to determine the 
answers: simply asking the students. As evidenced in the previous chapter, students responded to an open-ended question, "I would reassess more often if..." The most common response from students was that they didn't need to--that their scores were good enough. While that supports the survey figure of $19 \%$ of students reassessing after already reaching a score of " 3 ," only $1 / 3$ of students at FMS are performing at grade level ability as reflected by grade level benchmarking data, report card data and standardized assessment data. That could indicate a disconnect between students' perception of their academic ability and their actual performance on the assessments. The educational experience from this researcher leads to the assertion that students reassess when they believe their peak performance has been reached. It is feasible that a student end with a ' 2 ' while still demonstrating a Growth Mindset. Similarly, a student who continually reassesses to earn a '4' may be reinforcing an underlying fixed mindset. Empowering learners to recognize and achieve growth for personal success continues to be the mission of the school district. Utilizing a Growth Mindset to improve learning through a skills-based approach is the mechanism for that to occur. The challenge lies in identifying and quantifying personal success for students and aligning that to the expectations of educators.

Another finding from students was that they would reassess more often if the assessments weren't so difficult to begin with. The solution to that obstacle may lie with another theme that surfaced from other responses, which was to make re-assessments mandatory. Students shared that they would, indeed, reassess if they had to. However, mandating such a decision counteracts the efforts to follow the District's mission of empowering students to achieve growth for personal success. Therefore, mandating the process of reassessment is not a sustainable solution. Students also shared a desire to learn from their mistakes with specific and direct feedback from 
their teacher. As highlighted in the literature review, the concept of feedback is the crux of learning.

\section{Parent Involvement in Student Reassessment}

Research question two sought to find what role parent involvement plays in a students' choice to reassess. Sixteen parent interviews were conducted to hear from parents their thoughts behind Skills Based Reporting, including reassessment. Parents spoke strongly of the value they place in using mistakes as learning opportunities. They made it clear they want their children to succeed academically and in life. Parents spoke of the necessity of recognizing consequences are a result of actions. To that end, parents feel strongly that students should have some skin in the game with the assessment process, including being prepared for the initial assessment and having all of the formative requirements completed before being allowed to reassess. The parent interview participants spoke of the fact they are heavily involved in their student's education. Despite this fact, Skills Based Reporting is confusing to them and they often hear conflicting stories from their children and teachers about the reporting system. Further complicating matters for parents are two different approaches to implementing the scoring system between the middle and high schools. Namely, that letter grades are omitted at all grade levels but appear again at high school, seemingly contrasting the message and purpose of transitioning to SBR in the first place. Highlighting the parent interviews was the consistent message that parents, indeed, influence the reassessment process. Over $80 \%$ of students reported they would reassess with a "2." Each parent interview participant confirmed they require their child to reassess with a score of "2." Most interviewees also strongly encouraged their children (with some parents requiring them) to reassess with a 3 in attempts to earn a 4 . This logical conclusion illustrates that parents desire for their children to succeed. The more involvement and encouragement parents provide 
may influence the students' perception of personal success. Should students raise their own standard of personal success, the frequency of reassessment would most certainly follow.

It was made evident from the parent interviews the necessity for the school to leverage parents' best interest and influence in their children's lives to enhance the reassessment process. For this to happen, parents will need to be methodically and intentionally taught the Skills Based process in a consistent manner that continues throughout their child's progression through the school system. Embedded within the parent education should be each component that comprised the theoretical framework of this study: Visible Learning Theory, Balanced Assessment Theory and Mindset Theory. FMS and FHS currently provide parents SBR literature in the form of an assessment handbook. Occasional SBR information nights with guest speakers are held for parents to ask questions of teachers and administrators. Students and teachers have also created various videos to help illustrate components of SBR.

Peter Senge, a leading organizational researcher, identified six essential elements that combine to bring about authentic change. Those elements include trust, vision, skills, resources, payoff and action plan. Should one of the elements be missing, the desired results are not achieved (Senge, 2006). In this SBR scenario, one could argue that parents are missing the vision and skills for effective change to SBR. According to Senge, this will result in confusion and anxiety. The parent interviews confirmed those collective feelings.

\section{Recommendations for Action}

The findings from this study are intended to guide improvement strategies that will improve student learning. One such improvement strategy is to establish consistent protocols for teacher feedback and controls to monitor, yet not inhibit student reassessment. Teachers must provide meaningful feedback in a timely fashion but also have a repertoire of ways to support the 
additional learning of each student. As highlighted in the literature review, the concept of feedback is the crux of learning. Mandating this process in some fashion may improve the likelihood of whether a student chooses to reassess but is not a sustainable solution as it removes the student ownership component. The study found a disconnect between students' perception of their academic ability and their actual performance on the assessments. Accurate feedback for students would create a more accurate description of his/her ability (Guskey, 2015). Feedback is what should comprise most of our discourse, with grades being a minute percentage of that. However, it is often the other way around. One strategy of formalizing the feedback process is to delay the grade and embed 'unofficial reassessments.'

The second recommended improvement strategy is to implement training for students and teachers around challenging learning procedures. Hattie (2018) and Nottingham (2017) connect challenging learning opportunities to student ownership, perseverance and positive learning outcomes. However, less than half of students reported that they continue working quite well or extremely well when struggling on an assessment. Furthermore, students stated they avoided reassessments because of the difficulty of the tasks they were asked to complete. Different learning experiences including hands-on projects and problem-based learning opportunities should be included in reassessment opportunities and not limited to paper and pencil products. Combined with instructional practices that include clear success criteria and relevant targets for students, such tasks provide a rigorous learning environment that is also engaging. Another action to complement the challenging learning concept is to implement a daily advisory course in middle school with an emphasis on college, career, life readiness with embedded Growth Mindset skill development. Furthermore, including a parental involvement element to these 
advisory classes would better integrate parents into the conversation around Growth Mindset, perseverance and how those qualities pave the way to college and career planning.

A third recommended improvement strategy as a result of the findings of this study is to provide consistent reassessment options for students. Currently each teacher arranges his/her reassessment schedule with students on an individual basis. Formalizing and streamlining this process that establishes a building-wide routine with established and consistent timelines and locations for reassessments may provide students the structure and clarity that would result in more reassessment efforts.

The final recommended improvement strategy is to enhance parent education around Skills Based Reporting. Workshop nights or classes with professionals from the field including teachers, college admission advisors, researchers and other education experts would provide a more holistic and extensive look at Skills Based Reporting. Consistent offerings like this would provide parents exposure into examining SBR through an educational lens. Furthermore, it would provide parents a chance to hear fresh voices and perspectives around the concept and recognize the scope of its implementation beyond this local school district.

\section{Contributions to the Body of Literature}

Competency-based learning is on the rise (Marzano, Norford, Finn, \& Finn III, 2017). With a growing number of schools, districts and states across the nation adopting elements of competency-based learning like Skills Based Reporting, more educational leaders will look to the body of research to guide their implementation efforts. This study in particular helps to fill a void in the literature around Skills Based Reporting, a unique variation of competency-based learning, at the middle school level. This study combines literature on Growth Mindset, student ownership of learning, and parent involvement to highlight the benefits and challenges 
surrounding the sustained implementation of this process. Specifically, this study's examination of reassessment procedures from both the student and parent perspective issues important feedback to not only the school participating in the study but to the numerous districts pursuing or contemplating the pursuit of a system like Skills Based Reporting.

\section{Limitations}

Despite the controls and methods used to establish reliability and validity, this study did present some limitations. For instance, parent participants were selected based on their responses to the recruitment letter. This process inevitably leads to parents participating in the study that are already involved in their child's education because they're actively reading and responding to email correspondence from their child's school. Other limitations of this study include the accuracy of students' response to the survey items as well as the self-selection of participants. While a genuine attempt for students to answer the questions in the most truthful and accurate manner are assumed, a risk is inherently involved with students providing inaccurate information. For example, in this study students provided retrospective data from memory. Another limitation included the omission of teachers from this study. The desire for this researcher was to narrow the focus to students and parents, specifically, but including teachers would provide an avenue to triangulate data points for a more robust picture of feedback surrounding Skills Based Reporting within this local context.

\section{Recommendation for Further Study}

The fact that nearly $100 \%$ of students felt their ability to learn, the amount of effort they put forth, and the ability to change their assessment score was in their control was an encouraging sign of a collective Growth Mindset. Despite those figures, it is unclear whether implementing SBR caused those beliefs. Future studies may include a focus on processes pre- 
SBR as compared to current processes and beliefs to better examine the effectiveness of sitebased implementation efforts.

Nearly $2 / 3$ of students said that they are quite likely or extremely likely to try again after failing to reach an academic goal. Consequently, another possible area of extension to this study would be to examine the goal setting process of students and teachers, including frequency, time and reflection. If students are likely to persevere to accomplish an academic goal, perhaps not having a goal from the onset of learning inhibits a student's desire to persevere. The Special Education population, specifically, is a subgroup that could be further studied within this problem of practice. Identifying how mindset impacts Special Education students, teacher and departmental processes, including the utilization of reassessment, including frequency, is something that would contribute to the body of research.

Further expanding this study could be a comparison of high school, middle school and elementary school students around the same reassessment parameters. Similarly, parents and teachers from each of these academic levels could be compared. A possible long-term study would be interesting to compare student reassessment practices at each level to post high school selection and success.

Finally, the study could be narrowed to examine teacher mindsets, specifically and compared to student reassessment trends in their content area or classes. Variations of this could include examining the mindsets of coaches and if a difference exists between teachers that coach and teachers that do not coach. Examining the variance in teacher reassessment practices and encouragements between subjects is another potential cycle of inquiry. For example, nearly $2 / 3$ of students reported they reassessed in math more than any other subject. 


\section{Conclusion}

This study provided the opportunity for students and parents to share their perceptions on Skills-Based Reporting in one middle-school setting. The study focused specifically on investigating how Skills Based Reporting impacted student mindset and to what extent parent involvement played a role in whether students chose to reassess or not to reassess. Findings from the study indicated that students generally believed they understood and demonstrated a Growth Mindset. Students believed it was possible for them to change their assessments score, level of effort and their ability to learn. Student participants indicated they only reassessed when they felt their score was not an accurate reflection of their learning. Sometimes, a score of a '2' matched the student view of their learning and should not automatically indicate the lack of a Growth Mindset. However, results suggested students do not fully embrace the central idea that they own their learning. Students reported they would reassess more frequently if it were required of them and if the assessments were not as difficult. Parent participants reported they were the ones that more often required reassessment rather than the teachers. A parent's high expectations are likely to result in more frequent reassessments, which does not necessarily reflect a Growth Mindset for the student. It was evident from this study that parents desire for their children to succeed. However, SBR clouds the ability for parents to easily identify where their child is in the learning

process. Parental fear of the unknown from this non-traditional assessment and reporting practice surfaces as a mixture of confusion and frustration.

The findings of the study support some components of the literature, particularly the crucial role that timely, substantial and specific feedback plays in the learning process. Meaningful and descriptive feedback on student learning is the hinge on which SBR and any 
other scoring mechanism swings. Furthermore, the study also supported literature that points out students benefit from having actively involved parents in the education process.

Considerations for further study were also provided. One consideration would be to measure the site-based effectiveness of SBR by examining mindsets before and after the implementation of SBR. Another consideration was to examine academic goal-setting procedures. Narrowing the focus to explore Special Education mindsets within SBR was another recommendation for future research. Finally, researching teacher mindset and perception around SBR is a consideration for further study and is likely to follow. 


\section{REFERENCES}

American Association of School Administrators. (2019, November 20). National College and Career Readiness Indicators. Retrieved from Redefining Ready: https://www.redefiningready.org/

Bartunek, J. M., \& Moch, M. K. (1987). First-Order, second-order, and third-order change and organization development interventions: A cognitive approach. The Journal of Applied Behavioral Science, 23(4), 483-500. https://doi.org/10.1177/002188638702300404

Bloomington-Normal Advantage. (2018). Essential employability skills. Bloomington, IL: McLean County Chamber of Commerce.

Brock, A., \& Hundley, H. (2016). The Growth Mindset coach; A teacher's month-by-month handbook for empowering students to achieve. Berkeley, CA: Ulysses Press.

Brookhart, S. M. (2011). Starting the conversation about grading. Educational Leadership, 69(3), 10. Retrieved from http://libproxy.lib.ilstu.edu/login?url=https://search.ebscohost.com/login.aspx?direc $\mathrm{t}=$ true $\& \mathrm{db}=\mathrm{ulh} \& \mathrm{AN}=66901493 \&$ site $=$ ehost-live $\&$ scope $=$ site

Brookhart, S. M. (2013). Assessing creativity. Educational Leadership, 70(5), 28. Retrieved from http://libproxy.lib.ilstu.edu/login?url=https://search.ebscohost.com/login.aspx?direc $\mathrm{t}=$ true $\& \mathrm{db}=\mathrm{ulh} \& \mathrm{AN}=85177948 \&$ site $=$ ehost-live $\&$ scope $=$ site

Bowen, C.-C. (2016). Straightforward statistics. Los Angeles: SAGE Publications.

Carnegie Project for the Educational Doctorate. (2018, October). About CPED. Retrieved from The CPED Initiative: https://www.cpedinitiative.org/page/AboutUs 
Center for Community College Student Engagement. (2019). A mind at work: Maximizing the relationship between mindset and student success. Austin, TX: The University of Texas at Austin, College of Education, Department of Educational Leadership and Policy, Program in Higher Education Leadership.

Clarke, V. \& Braun, V. (2013). Teaching thematic analysis: Overcoming challenges and developing strategies for effective learning. The Psychologist, 26(2), 120-123.

Colvin, Geoff. (2015). Humans are underrated: What high achievers know that brilliant machines never will. New York: Penguin.

Creswell, J.W. (2012). Educational research: Planning, conducting, and evaluating quantitative and qualitative research (4th ed.). Upper Saddle River, NJ: Merrill.

Creswell, J.W. (2014). Research design: Qualitative, quantitative, and mixed methods approaches (4th ed.). Thousand Oaks, CA: Sage.

Curwin, R. L. (2014). Can assessments motivate? Educational Leadership, 72(1), 38. Retrieved from http://libproxy.lib.ilstu.edu/login?url=https://search.ebscohost.com/login.aspx?direc $\mathrm{t}=$ true $\& \mathrm{db}=$ ulh $\& \mathrm{AN}=98177508 \&$ site $=$ ehost-live $\&$ scope $=$ site

Duckworth, A. (2016). Grit: The power of passion and perseverance. New York: Scribner.

DuFour, R., \& Marzano, R. J. (2011). Leaders of learning: How district, school, and classroom leaders improve student achievement. Bloomington, IN: Solution Tree Press.

DuFour, R., DuFour, r., \& Eaker, R. (2008). Revisiting professional learning communities at work: New insights for improving schools. Bloomington, IN: Solution Tree.

Dweck, C. S. (2006). Mindset: The new psychology of success; how we can learn to fulfill our potential. New York: Ballantine Books. 
Frey, N., Fisher, D., \& Hattie, J. (2018). Developing "assessment capable" learners: If we want students to take charge of their learning, we can't keep relegating them to a passive role in the assessment process. Educational Leadership, 75(5), 46. Retrieved from http://libproxy.lib.ilstu.edu/login?url=https://search.ebscohost.com/login.aspx?direc $\mathrm{t}=$ true $\& \mathrm{db}=\mathrm{ulh} \& \mathrm{AN}=128251778 \&$ site $=$ ehost-live $\&$ scope $=$ site

Goodwin, B., \& Hein, H. (2016). Evaluating and improving: Not the same thing. Educational Leadership, 73(8), 83. Retrieved from http://libproxy.lib.ilstu.edu/login?url=https://search.ebscohost.com/login.aspx?direc $\mathrm{t}=$ true $\& \mathrm{db}=\mathrm{ulh} \& \mathrm{AN}=115591956 \&$ site $=$ ehost-live \&scope $=$ site

Guskey, T. R. (2009). Practical solutions for serious problems in standards-based grading Thousand Oaks, CA: Corwin Press, c2009. Retrieved from http://libproxy.lib.ilstu.edu/login?url=https://search.ebscohost.com/login.aspx?direc $\mathrm{t}=$ true $\& \mathrm{db}=\mathrm{cat} 00180 \mathrm{a} \& \mathrm{AN}=$ milner $.1287970 \&$ site $=$ eds-live $\&$ scope $=$ site

Guskey, T. R. (2011). Five obstacles to grading reform. Educational Leadership, 69(3), 16.

\section{Retrieved}

from http://libproxy.lib.ilstu.edu/login?url=https://search.ebscohost.com/login.aspx?direc $\mathrm{t}=$ true $\& \mathrm{db}=\mathrm{f5h} \& \mathrm{AN}=66901494 \&$ site $=$ eds-live $\&$ scope $=$ site

Guskey, T. R. (2015). On your mark: Challenging the conventions of grading and reporting. Bloomington, IN: Solution Tree.

Guskey, T. R., \& Jung, L. A. (2013). Answers to essential questions about standards, assessments, grading, and reporting. Thousand Oaks, CA: Corwin, c2013. Retrieved from http://libproxy.lib.ilstu.edu/login?url=https://search.ebscohost.com/login.aspx?direc $\mathrm{t}=$ true $\& \mathrm{db}=\mathrm{cat} 00180 \mathrm{a} \& \mathrm{AN}=$ milner. $1634851 \&$ site $=$ eds-live $\&$ scope $=$ site 
Guskey, T. R., \& Jung, L. A. (2009). Grading and reporting in a standards-based environment: Implications for students with special needs. Theory into Practice, (1), 53. 10.1080/00405840802577619; 10.1080/00405840802577619 Retrieved from http://libproxy.lib.ilstu.edu/login?url=https://search.ebscohost.com/login.aspx?direc $\mathrm{t}=$ true $\& \mathrm{db}=\mathrm{edsj}$ sr\&AN=edsjsr.40071576\&site=eds-live \&scope=site

Guskey, T. R., Swan, G. M., \& Lee, A. J. (2011). Grades that mean something. The Phi Delta Kappan, (2), 52. Retrieved from http://libproxy.lib.ilstu.edu/login?url=https://search.ebscohost.com/login.aspx?direc $\mathrm{t}=$ true $\& \mathrm{db}=\mathrm{edsj}$ sr\&AN=edsjsr.23048946\&site=eds-live \&scope=site

Hattie, J. (2012). Visible Learning For Teachers: Maximizing impact on learning. New York: Routledge.

Hattie, J., Fisher, D., \& Frey, N. (2016). Do they hear you? Educational Leadership, 73(7), 16. Retrieved from http://libproxy.lib.ilstu.edu/login?url=https://search.ebscohost.com/login.aspx?direc $\mathrm{t}=$ true $\& \mathrm{db}=\mathrm{ulh} \& \mathrm{AN}=114581295 \&$ site $=$ ehost-live \&scope $=$ site

Hattie, J., \& Yates, G. C. (2014). Visible Learning and the Science of How We Learn. Routledge: New York.

Hattie, J., \& Zierer, K. (2018). 10 Mindframes for Visible Learning: Teaching for success. New York: Routledge.

Illinois State Board of Education. (2019, October 29). Academic Progress. From Illinois Report Card: https://www.illinoisreportcard.com/School.aspx? source=trends\&source2=iar\&Schoolid= 170640160261001 
Jung, L. A., \& Guskey, T. R. (2012). Grading exceptional and struggling learners Thousand Oaks: Corwin Press, c2012. Retrieved from http://libproxy.lib.ilstu.edu/login?url=https://search.ebscohost.com/login.aspx?direc $\mathrm{t}=$ true $\& \mathrm{db}=$ cat00180a $\& A N=$ milner.1447516\&site=eds-live $\&$ scope $=$ site

Marzano, R. J. (2000). Transforming classroom grading Alexandria, VA: Association for Supervision and Curriculum Development, c2000. Retrieved from http://libproxy.lib.ilstu.edu/login?url=https://search.ebscohost.com/login.aspx?direc $\mathrm{t}=$ true $\& \mathrm{db}=$ cat00180a $\& A N=$ ilner.1948902\&site=eds-live \&scope $=$ site

Marzano, R. J., \& Heflebower, T. (2011). Grades that show what students know. Educational Leadership, 69(3), 34-39. Retrieved from http://libproxy.lib.ilstu.edu/login?url=https://search.ebscohost.com/login.aspx?direc $\mathrm{t}=$ true $\& \mathrm{db}=$ eft $\& A N=525580675 \&$ site $=$ eds-live $\&$ scope $=$ site

Marzano, R. J., Norford, J. S., Finn, M., \& Finn III, D. (2017). A handbook for personalized competency-based education. Bloomington, IN: Marzano Research.

Merriam, S. B. (2009). Qualitative research: A guide to design and implementation. San Francisco, CA: Jossey Bass.

Mintrop, R. (2016). Design-Based School Improvement: A practical guide for education leaders. Cambridge: Harvard Education Press.

Muñoz, M. A., \& Guskey, T. R. (2015). Standards-based grading and reporting will improve education. Phi Delta Kappan, 96(7), 64. 10.1177/0031721715579043 Retrieved from http://libproxy.lib.ilstu.edu/login?url=https://search.ebscohost.com/login.aspx?direc $\mathrm{t}=$ true $\& \mathrm{db}=\mathrm{f} 5 \mathrm{~h} \& \mathrm{AN}=101691443 \&$ site $=$ eds-live $\&$ scope $=$ site 
Nottingham, J. (2017). The Learning Challenge: How to guide your students through the learning pit to achieve deeper understanding. Thousand Oaks, CA: Corwin.

O'Connor, K., \& Wormeli, R. (2011). Reporting student learning. Educational Leadership, 69(3), 40. Retrieved from http://libproxy.lib.ilstu.edu/login?url=https://search.ebscohost.com/login.aspx?direc $\mathrm{t}=$ true $\& \mathrm{db}=u$ lh $\& \mathrm{AN}=66901499 \&$ site $=$ ehost-live $\&$ scope $=$ site

Pink, D. (2009). Drive: The surprising truth about what motivates us. New York: Penguin Group.

Reeves, D. B. (2008). Effective grading Association for Supervision \& Curriculum Development. Retrieved from http://libproxy.lib.ilstu.edu/login?url=https://search.ebscohost.com/login.aspx?direc $\mathrm{t}=$ true $\& \mathrm{db}=\mathrm{f} 5 \mathrm{~h} \& \mathrm{AN}=31501221 \&$ site $=$ eds-live $\&$ scope $=$ site

Reeves, D. B. (2011). Taking the grading conversation public. Educational Leadership, 69(3), 76-79. Retrieved from http://libproxy.lib.ilstu.edu/login?url=https://search-proquestcom.libproxy.lib.ilstu.edu/docview/1018483049?accountid=11578

Reeves, D. B. (2013). Four ways to make grades more effective. Educational Horizons, 91(2), 28-29. Retrieved from http://libproxy.lib.ilstu.edu/login?url=https://search.ebscohost.com/login.aspx?direc $\mathrm{t}=$ true $\& \mathrm{db}=$ eric $\& A N=\mathrm{EJ} 999527 \&$ site $=$ edslive\&scope=site http://pilambda.org/horizons/four-ways-to-make-grades-more-effective/ 
Reeves, D., Jung, L. A., \& O'Connor, K. (2017). Special topic: What's worth fighting against in grading? Educational Leadership, 74(8), 42-45. Retrieved from http://libproxy.lib.ilstu.edu/login?url=https://search.ebscohost.com/login.aspx?direc $\mathrm{t}=$ true $\& \mathrm{db}=$ eric $\& \mathrm{AN}=\mathrm{EJ} 1140461 \&$ site $=$ edslive\&scope=site http://www.ascd.org/publications/educationalleadership/may17/vol74/num08/What's-Worth-Fighting-Against-inGrading\%C2\%A2.aspx

Reeves, D., Lee, A. J., \& O’Connor, K. (2017). What's worth fighting against in grading? Educational Leadership, 74(8), 42. Retrieved from http://libproxy.lib.ilstu.edu/login?url=https://search.ebscohost.com/login.aspx?direc $\mathrm{t}=$ true $\& \mathrm{db}=\mathrm{ulh} \& \mathrm{AN}=122878943 \&$ site $=$ ehost-live $\&$ scope $=$ site

Schimmer, T. (2016). Grading from the inside out: Bringing accuracy to student assessment through a standards-based mindset (1st ed.). Bloomington, Indiana: Solution Tree Press. Retrieved from http://ebookcentral.proquest.com/lib/[SITE_ID]/detail.action?docID=5197958

Scriffiny, P. L. (2008). Seven reasons for standards-based grading. Educational Leadership, 66(2), 70. Retrieved from http://libproxy.lib.ilstu.edu/login?url=https://search.ebscohost.com/login.aspx?direc $\mathrm{t}=$ true $\& \mathrm{db}=f 5 \mathrm{~h} \& \mathrm{AN}=34967544 \&$ site $=$ eds-live $\&$ scope $=$ site

Senge, P. (2006). The Fifth Discipline: The art \& practice of the learning organization. New York: Doubleday.

Stiggins, R. (2005). From formative assessment to assessment for learning: A path to success in standards-based schools. Phi Delta Kappan, 87(4), 324-328. 
Stiggins, R. (2009). Assessment "for" learning in upper elementary grades. Phi Delta Kappan, 90(6), 419-421. Retrieved from http://libproxy.lib.ilstu.edu/login?url=https://search.ebscohost.com/login.aspx?direc $\mathrm{t}=$ true $\& \mathrm{db}=$ eric \&AN=EJ829691\&site $=$ ehost live\&scope=sitehttp://www.pdkmembers.org/members_online/members/orders.asp?actio $\mathrm{n}=$ results $\& \mathrm{t}=\mathrm{A} \& \mathrm{desc}=\& \mathrm{tex} \mathrm{t}=\&$ Iname_1=Stiggins\&fname_1=Rick\&lname_2=\&fname_2 $=\& \mathrm{kw} \_1=\& \mathrm{kw} \_2=\& \mathrm{kw} \_3=\& \mathrm{kw} \_4=\& \mathrm{mn} 1=02 \& \mathrm{yr} 1=2009 \& \mathrm{mn} 2=\& \mathrm{yr} 2=\& \mathrm{c} 1=$

Teddlie, C., \& Tashakkori, A. (2009). Foundations of mixed methods research: Integrating quantitative and qualitative approaches in the social and behavioral sciences. Thousand Oaks, CA: Sage.

The College Board. (2019, November 1). K-12 Reporting Portal. From College Board: https://k12reports.collegeboard.org/home\#reports

Tough, P. (2012). How children succeed: Grit, curiosity, and the hidden power of character. Boston: Mariner Books.

Townsley, M., \& Buckmiller, T. (2016). What does the research say about standards-based grading?: A research primer. Retrieved from http://mctownsley.net/standards-basedgrading-research/

Townsley, M. (2018). Mastery-minded grading in secondary schools. School Administrator, 75(2), 16-21. Retrieved from http://libproxy.lib.ilstu.edu/login?url=https://search.ebscohost.com/login.aspx?direc $\mathrm{t}=$ true $\& \mathrm{db}=\mathrm{eft} \& \mathrm{AN}=127699253 \&$ site=eds-live $\&$ scope $=$ site 
Tucker, C. (2018). Rethinking grading: Making mastery, not points, the reward for your students. Educational Leadership, 75(5), 84. Retrieved from http://libproxy.lib.ilstu.edu/login?url=https://search.ebscohost.com/login.aspx?direc $\mathrm{t}=$ true $\& \mathrm{db}=$ ulh \&AN=128251787\&site=ehost-live \&scope $=$ site

Vatterott, C. (2015). Rethinking grading: Meaningful assessment for standards-based learning. Alexandria, VA: ASCD, 2015]. Retrieved from http://libproxy.lib.ilstu.edu/login?url=https://search.ebscohost.com/login.aspx?direc $\mathrm{t}=$ true $\& \mathrm{db}=$ cat00180a $\& \mathrm{AN}=$ milner.1784869\&site=eds-live \&scope=site

Wiliam, D. (2012). Feedback: Part of a system. Educational Leadership, 70(1), 31. Retrieved from http://libproxy.lib.ilstu.edu/login?url=https://search.ebscohost.com/login.aspx?direc $\mathrm{t}=$ true $\& \mathrm{db}=\mathrm{ulh} \& \mathrm{AN}=82055859 \&$ site $=$ ehost-live $\&$ scope $=$ site

Wormeli, R. (2011). Redos and retakes done right. United States: ASCD ASSOCIATION FOR SUPERVISION AND. Retrieved from http://libproxy.lib.ilstu.edu/login?url=https://search.ebscohost.com/login.aspx?direc $\mathrm{t}=$ true $\& \mathrm{db}=\mathrm{edsbl} \& \mathrm{AN}=\mathrm{RN} 301741775 \&$ site=eds-live $\&$ scope $=$ site

Wormeli, R. (2006). Fair isn't always equal: Assessing grading in the differentiated classroom. Portland, ME: Stenhouse.

Wormeli, R. (2011b). Redos and retakes done right. Educational Leadership, 69(3), 22. Retrieved from http://libproxy.lib.ilstu.edu/login?url=https://search.ebscohost.com/login.aspx?direc $\mathrm{t}=$ true $\& \mathrm{db}=\mathrm{ulh} \& \mathrm{AN}=66901495 \&$ site $=$ ehost-live $\&$ scope $=$ site 
Wormeli, R. (2016). What does data tell us about inequity? Educational Leadership, 74(3), 9.

\section{Retrieved}

from http://libproxy.lib.ilstu.edu/login?url=https://search.ebscohost.com/login.aspx?direc $\mathrm{t}=$ true $\& \mathrm{db}=\mathrm{ulh} \& \mathrm{AN}=119446315 \&$ site $=$ ehost-live $\&$ scope $=$ site

Visible Learning. (2019, August 19). Professor John Hattie. From Visible Learning: https://visible-learning.org/john-hattie/

Vogt, W. P., Gardner, D. C., \& Haeffele, L. M. (2012). When to Use What Research Design. New York: Guilford Press.

Vogt, W. P., Vogt, E. R., Gardner, D. C., \& Haeffele, L. M. (2014). Selecting the Right Analyses for Your Data: Quantitative, qualitative, and mixed methods. New York: Guilford Press. 


\section{APPENDIX A:RECRUITMENT LETTER/EMAIL}

\section{Dear Parent,}

I am completing a research study investigating how Skills Based Reporting has impacted student mindset. I am inviting your participation which will involve one audio-recorded interview with me that will take place in a location convenient to you. I expect the interview to last approximately 30 - 45 minutes. The questions will relate to your thoughts and experiences with perseverance and student assessment.

Your participation is voluntary. You will not be treated differently based on whether you choose to participate or choose not to participate. If you would like to be a part of this research study, please respond to this e-mail. I will contact you within $1-2$ days to set up a convenient time for the interview.

Thank you very much for your time and interest in this study. Your opinions will be invaluable to the success of this research study.

Sincerely,

Ben Lee 


\section{APPENDIX B: INFORMED CONSENT LETTER}

\section{Dear Parent:}

I am conducting a research study to investigate the impact that Skills Based Reporting has had on student mindset. I am inviting your participation, which will involve one interview with me that will take place at a location convenient to you and last about 30-45 minutes. The interview will be audio recorded, with your permission.

Your participation in this study is voluntary. If you choose not to participate or to withdraw from the study at any time, there will be no penalty of any kind. Your decision to participate or not to participate will not affect you or your student's treatment by school personnel in any way. The results of the study will be used in a written report and oral presentation and may later be used for a dissertation study, but your name will never be used. I will take all precautions to maintain your confidentiality. Pseudonyms will be used during the interview and in the final report.

There is minimal physical, psychological or social risks to this research study. For example, you may feel uncomfortable sharing your true feelings about the discussion questions. Please be assured that no information that you reveal in the interview will be shared with anyone at Farmersville CUSD \#16. To minimize risk, interviews will be conducted in settings that provide the maximum amount of privacy and confidentiality to you. And of course, you have the right to refuse to answer any questions during the interview. The possible benefit of your participation would be to reflect upon your own experiences and those of your child regarding Growth Mindset to improve the assessment process at OMS. Your data, even if deidentified, will not be used in other research projects. You are ineligible to participate if you are currently within the European Economic Area.

If you have any questions concerning the research study, please call me at (309) 379-5941.

Sincerely,

Ben Lee

I give consent to participate in the above study. 
Signature

Date

I give consent for my interview to be audiotaped.

Signature

Date

If you have any questions about your rights as a subject/participant in this research, or if you feel you have been placed at risk, you can contact the Research Ethics \& Compliance Office at Illinois State University at (309) 438-2529. 


\section{APPENDIX C: PARENT PERMISSION/ASSENT FORM}

Dear Parent:

You are being asked to allow your child to participate in a research study I am conducting along with Dr. Guy Banicki of the Education Foundations and Administration (EAF) Department at Illinois State University. I will be investigating the impact that Skills Based Reporting has had on student mindset at Farmersville Middle School. Your child has been asked to participate because she/he is a student at Farmersville Middle School.

Their participation in this study is voluntary. Neither you nor your child will be penalized if he/she chooses to skip parts of the study, not participate, or withdraw from the study at any time. If you choose to allow your child to participate in this study, he/she will complete an online survey. Your child's responses will be anonymous; nothing that will identify him/her will be linked to his/her responses. The survey will take approximately 15-20 minutes to complete. The results of the study will be used in a written report and oral presentation and may later be used for a dissertation study, but your child's name will never be used.

The possible benefit of your child's participation would be to reflect upon his/her experiences regarding Growth Mindset to improve the assessment process at OMS. We do not anticipate any risks beyond those that would occur in everyday life.

If you have any questions concerning the research study, please call me at (309) 379-5941.

Sincerely,

Ben Lee

If you choose to allow your child to participate in this study, no further action is needed. If you do not wish for your child to participate in the study, sign and return this form [within three weeks of receiving this form]. Only sign below if you do NOT wish for your child to participate in the study.

Signature

Date 
If you have any questions about your child's rights as a subject/participant in this research, or if you feel you have been placed at risk, you can contact the Research Ethics \& Compliance Office at Illinois State University at (309) 438-5527 or IRB @ilstu.edu. 


\section{APPENDIX D: STUDENT ASSENT}

[The following will be included on a cover page before students begin the survey]

\section{Dear Student/Participant--}

You are being asked to take a short survey to help provide information about Skills Based Reporting at Farmersville Middle School. This survey is being used as part of a research study done by Mr. Lee and Dr. Guy Banicki, Associate Professor at Illinois State University (ISU). Doing this survey is voluntary. You will not be in trouble if you choose not to participate. Your answers will be secret; no one will be able to identify you from your responses. The survey will take about 15-20 minutes to finish. By taking the survey you will help improve Skills Based Reporting at OMS.

We do not anticipate any risks beyond those that would occur in everyday life.

Please click this box to begin the survey. [link must be clicked to begin survey] 


\section{APPENDIX E: STUDENT SURVEY PROTOCOL}

1. What is your gender?

(male, female)

2. Which town is listed on your primary home address?

(Waynesville, Atlanta, McLean, Armington, Minier, Hopedale, Stanford, Danvers, Bloomington, other)

3. Do you take an Advanced Placement class (Algebra or Advanced English)?

(yes, no)

4. Do you participate on a school team or activity?

(yes, no)

5. How many times have you re-assessed this semester?

$(0 ; 1-3 ; 4-6 ; 7-9 ; 10+)$

6. In which subject do you reassess the most?

(English, Math, Science, Social Studies, Encore)

7. I am more likely to reassess if I like the subject.

(strongly agree, agree, undecided, disagree, strongly disagree)

8. Learning about the Spartan Skill of perseverance encourages me to reassess, even when I don't have to.

(strongly agree, agree, undecided, disagree, strongly disagree)

9. When I earn a "2" I am likely to reassess in hopes of earning a 3. (strongly agree, agree, undecided, disagree, strongly disagree)

10. When I earn a "3" I am likely to reassess in hopes of earning a 4. (strongly agree, agree, undecided, disagree, strongly disagree)

11. If you fail to reach an important goal, how likely are you to try again?

(extremely likely, quite likely, somewhat likely, slightly likely, not at all likely)

12. When you are working on a project that matters a lot to you, how focused can you stay when there are lots of distractions?

(extremely focused, quite focused, somewhat focused, slightly focused, not at all focused)

13. In school, how possible is it for you to change: Being talented

(completely possible to change, quite possible to change, somewhat possible to change, a little possible to change, not at all possible to change) 
14. In school, how possible is it for you to change: Giving a lot of effort

(completely possible to change, quite possible to change, somewhat possible to change, a little possible to change, not at all possible to change)

15. In school, how possible is it for you to change: Your level of intelligence (completely possible to change, quite possible to change, somewhat possible to change, a little possible to change, not at all possible to change)

16. I would reassess more often if.... (short response) 


\section{APPENDIX F: PARENT INTERVIEW PROTOCOL}

1. Which of your children currently attend FMS? Is he/she the youngest/oldest?

2. In which town do you currently reside?

3. Generally speaking, do you think people should be given second chances? Please explain.

4. If given the choice, do you believe your son/daughter would reassess to improve his/her score? Please explain.

5. [The school] requires students to reassess if earning a 1 on an assessment. A student who earns a 2 or 3 has the option to reassess. If your child has the opportunity to retake an assessment, would you expect him/her to take advantage of that [If he earned a 2, would you expect him to try for a 3 ? What about going from a 3 to a 4 ?]

6. If your child was able to reassess but chose not to, would you want to be notified? Please explain.

7. How often have you spoken to your child or a teacher regarding reassessments this school year?

8. Do you think your child can reach his/her maximum potential without taking risks? Please explain.

9. Which is more important to you--for your child to earn the highest score or to demonstrate a Growth Mindset? Please explain.

10. Do you think your child perseveres when facing academic challenges? Please explain.

11. Many of our students do not take advantage of reassessing to improve their performance. Why do you think that is? 